Syntactic adaptation depends on perceived linguistic knowledge: native English speakers differentially adapt to native and non-native confederates in dialogue

Jia E. Loy \& Kenny Smith University of Edinburgh

Author Note

This research received funding from the European Research Council (ERC) under the European Union's Horizon 2020 research and innovation programme (grant agreement 681942), held by KS. The funders had no role in the study design, data collection and analysis, decision to publish, or preparation of the manuscript.

Data for this project is available on the Open Science Framework repository https://osf .io/njxg8/

Corresponding author: Jia E. Loy (email: jia.loy@ed.ac.uk) 


\begin{abstract}
The way speakers adapt their language during interaction may be influenced by their perception of their partner's linguistic knowledge. We examined the degree to which speakers adapt to the syntactic structures used by their interlocutor, comparing interaction between native speakers of English and a partner who was a native or a nonnative speaker. In three lab-based experiments, naive participants took turns to describe and match pictures with a confederate who was a native or nonnative speaker of English. We found that participants tended to produce the same syntactic form (prepositional object or double object) that the confederate had just produced on the turn before. We observed different levels of adaptation to native and nonnative confederates, with participants adapting more to nonnative confederates than native confederates, but only when confederates exhibited linguistic inflexibility through a rigid production of double object constructions, some of which were ungrammatical (e.g. "The wizard donates the golfer the cake"). A further two online experiments were conducted to replicate the design of the lab-based experiments. We found differential adaptation to natives and nonnatives again only when confederates' behaviour exhibited the same linguistic inflexibility; however, the effect of confederate nativeness was the opposite to the lab experiments, with participants adapting more to the inflexible native speaker. Together, our results provide evidence that adaptation is at least partly driven by listener-oriented mechanisms; speakers take into account their partner's linguistic knowledge and communicative needs when these needs are foregrounded by the communicative context.
\end{abstract}

Keywords: adaptation, dialogue, native-nonnative interaction 


\section{Syntactic adaptation depends on perceived linguistic knowledge: native English speakers differentially adapt to native and non-native confederates in dialogue}

\section{Introduction}

In conversational interaction, interlocutors often adapt their speech in response to their partner's. This phenomenon has been studied extensively under various terms, including priming (Branigan, Pickering, \& Cleland, 2000; Hartsuiker, Bernolet, Schoonbaert, Speybroeck, \& Vanderelst, 2008; Hartsuiker, Pickering, \& Veltkamp, 2004), accommodation (Giles, 1973; Giles \& Ogay, 2008; Shepard, Giles, \& Le Poire, 2001), alignment (Branigan, Pickering, Pearson, McLean, \& Brown, 2011; Pickering \& Garrod, 2004, 2006), audience design (Clark, 1996; Clark \& Murphy, 1983; Horton \& Gerrig, 2005), entrainment (Beňuš, Levitan, \& Hirschberg, 2012; Brennan \& Clark, 1996), and synchrony (Ireland \& Pennebaker, 2010). ${ }^{1}$

The present study focusses on syntactic adaptation, exploring how a speaker's inferences about their interlocutor's linguistic knowledge influence the way in which they adapt to their interlocutors. We use a confederate priming paradigm to explore how native English speakers adapt to either a native or nonnative interlocutor; native-nonnative interaction provides an ideal test-case for our question, since factors such as differing levels of linguistic proficiency (Y. Kim \& McDonough, 2008) or a lack

\footnotetext{
${ }^{1}$ The disparity in terminology reflects inconsistency in the literature on the interchangeability of terms, as well as the cognitive mechanisms underlying each (for example, Brennan, Galati, and Kuhlen (2010) distinguish between entrainment and alignment, while Nenkova, Gravano, and Hirschberg (2008) and Iio et al. (2015) use the two interchangeably). In the current study, we opt for the more neutral term "adaptation".
} 
of shared background between interlocutors (Varonis \& Gass, 1985) might hamper communication in such contexts, leading native speakers to adapt. Evidence from native-nonnative communicative tasks for example suggests that native speakers tend to speak slower and hyperarticulate or adopt a simpler syntax when conversing with a nonnative speaker (Biersack, Kempe, \& Knapton, 2005; Ferguson, 1975; Papoušek \& Hwang, 1991; Scarborough, Dmitrieva, Hall-Lew, Zhao, \& Brenier, 2007; Uther, Knoll, \& Burnham, 2007). Much of prior work, however, has relied on measures based on speakers' owns introspections, unstructured interactions, or utterances directed at imaginary rather than actual conversation partners. While such methods provide an insight into the linguistic modifications characteristic of nonnative-directed speech, they fall short of demonstrating explicit adaptation towards a nonnative interlocutor's speech. Thus, they do not distinguish between adjustments arising from the native speaker's model of a hypothetical nonnative interlocutor, and those from an adaptive mechanism in communicatively authentic situations. In the current study, we situate interaction within a controlled, face-to-face communicative task; we use a dialogue game in which speakers are given the opportunity to adapt to the (scripted) syntactic forms uttered by their partner in a previous turn. We consider the degree to which this type of adaptation may be driven by speakers' inferences about their partner's needs, knowledge or characteristics in the given moment.

\section{Mechanisms for adaptation}

Adaptation occurs at many levels of linguistic structure, from speech rate (Giles \& Coupland, 1991; Staum Casasanto, Jasmin, \& Casasanto, 2010) and phonetic realisations (Hwang, Brennan, \& Huffman, 2015; M. Kim, Horton, \& Bradlow, 2011) to speakers' choice of words (Branigan et al., 2011; Brennan \& Clark, 1996) and syntactic 
forms (Cleland \& Pickering, 2003). Syntactic adaptation, which is our focus here, has been shown to extend across different types of sentences (Gries, 2005; Reitter \& Moore, 2006; Savage, Lieven, Theakston, \& Tomasello, 2003; Trofimovich, Mcdonough, \& Neumann, 2013), and even occurs between languages in bilinguals (Hartsuiker et al., 2004; Loebell \& Bock, 2003). The extent of adaptation may also be modulated by factors such as speaker gender (Ireland \& Pennebaker, 2010), working memory capacity (Foltz, Thiele, Kahsnitz, \& Stenneken, 2015) or repetition of lexical information (the so-called lexical boost effect; Cleland \& Pickering, 2003).

Syntactic coordination between speakers has been explained in terms of priming processes, in which speakers are likely to repeat information that they have recently been exposed to. These accounts emphasise a mechanism that is largely automatic and unconscious, whereby encountering a particular form (e.g. a passive) causes the mental representations associated with that form to be more highly activated, increasing the likelihood that the speaker reuses them later (Pickering \& Branigan, 1998; Pickering \& Garrod, 2004). Experiments show for example that speakers are likely to repeat the same grammatical structure used either by themselves or their partner previously, suggesting that recently-encountered forms are more available during production than an alternative, unheard structure (Bock, 1986; Branigan et al., 2000; Levelt \& Kelter, 1982). Consequently, the magnitude of the effect declines with the interval since the prime was presented, as activated representations decay over time (Branigan, Pickering, \& Cleland, 1999; Hartsuiker et al., 2008).

Priming-based accounts for adaptation receive support from a cognitive efficiency perspective. For example speakers tend to produce the same sentence structures over a short period, even across variations in the idea being expressed (Bock \& Loebell, 1990) 
or at the expense of clarity of the message (e.g. saying "Put the sheep on the plate on the circle", where "on the plate" is temporarily ambiguous as a modifier or a destination; Haywood, Pickering, \& Branigan, 2005). Similarly, speakers entrained on a particular lexical expression (e.g. "the pennyloafer") with a partner persist in using the same expression on later trials despite a more basic-level term (e.g. "the shoe") being sufficient (Brennan \& Clark, 1996). Such findings support the notion of a mechanistic, implicit process by which interlocutors are influenced by each other's linguistic behaviour without conscious awareness or explicit negotiation (Pickering \& Garrod, 2004, 2006). Consequently, priming-based adaptation is assumed to be largely "egocentric" to the speaker, arising as an involuntary by-product of perceiving another's behaviour rather than a strategic interactional decision. The idea of an automatic, resource-free mechanism holds intuitive appeal given the seemingly effortless nature with which conversation unfolds between individuals, and is consistent with the observation that speakers in experiments are often unaware of repeating their partner's structures (Pickering \& Branigan, 1998).

Automatic priming however does not appear to provide the full picture. Some researchers argue that the priming effects observed in experimental studies may not generalise to ordinary conversation, where other factors such as interpersonal processes come into play. In a corpus-based analysis of syntactic and lexical similarity within and between speakers, Healey, Purver, and Howes (2014) found no evidence for syntactic consistency between speakers' turns once lexical overlap had been controlled for (cf. Fernández \& Grimm, 2014). Healey et al. concluded that speakers are not influenced by their partner's syntactic choices, but rather, repeat each other's words in different syntactic contexts to achieve a variety of functions such as humour, irony, disagreement, 
and appraisal. While their results are difficult to reconcile with other studies which do report syntactic priming while controlling for verb overlap (e.g., Jaeger \& Snider, 2013; Reitter \& Moore, 2006), they nevertheless highlight the contribution of alternative mechanisms to adaptation between speakers.

Indeed, the automaticity of priming leaves little room for the range of social influences underlying interaction by which interlocutors take into account non-linguistic as well as linguistic information to achieve successful dialogue. Speakers have been shown to build complex situation models by which they track their interlocutor's perspective or mental state, bringing such information to bear during the speech planning process (Brennan et al., 2010). There is ample evidence, for instance, of a reflective component to communication by which interlocutors model their partner's mental state. Such information is brought to bear during speech planning, shaping the speaker's utterance with respect to their interlocutor. Importantly, this process of interlocutor-modelling can lead to adaptation as speakers formulate utterances with respect to specific conversation partners. Therefore, under this account adaptation is fundamentally listener-oriented. Such adaptation can arise through different mechanisms.

Speakers' utterances may be influenced by a process known as audience design, whereby communicative behaviour is tailored to the specific needs or characteristics of one's interlocutor (Clark, 1996; Clark \& Murphy, 1983; Clark \& Schaefer, 1987). Clark and colleagues propose that speakers design their utterances not just for anyone, but that they are "intended for particular listeners with particular momentary thoughts and beliefs", with the expectation that "listeners ... in turn, make essential use of this fact in understanding that utterance" (Clark \& Murphy, 1983, p.287). In other words, speakers 
may convey the same meaning differently depending on who they are conversing with.

Audience design is supported by evidence from referential communication studies involving interaction between participants. For example, Brennan and Clark (1996) observed a partner-specific effect on lexical entrainment: When interacting with a new partner, speakers were more likely to abandon previously entrained-upon over-informative expressions such as "the pennyloafer" for simpler, basic-level terms like "shoe". This suggests that the priming of lexical choice may be mediated at least in part by interlocutor-specific considerations whereby speakers evaluate the expressions that their current partner are likely to understand. Listeners likewise adapt how they interpret an expression depending on who says it: Participants in Metzing and Brennan (2003) experienced a processing delay when their partner departed from an entrained-upon expression (e.g. "the shiny cylinder") for a new expression (e.g. "the silver pipe"), but not when these new expressions were uttered by a different partner (cf. Matthews, Lieven, \& Tomasello, 2010). These findings are consistent with accumulating evidence that speakers can rapidly integrate information about their partner's perspective during communication (Brennan \& Hanna, 2009; Hanna \& Tanenhaus, 2004; Lockridge \& Brennan, 2002), and point towards a flexible, audience-oriented mechanism underlying speaker adaptation. ${ }^{2}$

\footnotetext{
${ }^{2}$ Note that there is contrary evidence to show that speakers may not always take partner-specific information into account - for example, factors such as time pressure (Horton \& Keysar, 1996) or a lower working memory capacity (Wardlow, 2013) reduce the likelihood that speakers consider their partner's perspective. Similar effects of egocentricity have also been found in listeners' behaviour on comprehension tasks (Barr, 2008; Epley, Morewedge, \& Keysar, 2004; Keysar, Lin, \& Barr, 2003). Although these studies do not focus on adaptation, they nonetheless raise questions about the circumstances under which audience design may influence speakers' behaviour.
} 
Audience design may also be driven by a speaker's own beliefs or inferences about their interlocutor's communicative needs. Branigan et al. (2011) found that participants were more likely to repeat a dispreferred name (e.g. "coach" for a bus) used by their partner if they believed their partner was a less capable, "basic" computer compared to an "advanced" one. Such adaptation can extend beyond lexical choice to the forms of speakers' utterances. Speakers may formulate their utterances based on inferences about their partner's linguistic preferences: Bortfeld and Brennan (1997) found that native speakers of English often adopted idiosyncratic descriptions judged as less natural by other native speakers (e.g. "you can shake your body" for a rocking chair) that their nonnative partners showed a preference for; participants' rate of selecting the correct pictured being described improved over trials, suggesting that native speakers sacrificed idiomaticity and naturalness in favour of comprehensibility for their partner. Beliefs based on a partner's language background may also include ideas about their linguistic knowledge, in particular the grammatical structures which may be available to them. In his characterisation of "foreigner talk", Ferguson $(1971,1975)$ highlights a variety of alterations that native speakers might make in interaction with nonnative speakers, often with the aim of simplifying their language use. These observations, together with the modulating effect of partner-based inferences in referential communication, suggest that speakers take into account (their perception of) their partner's linguistic capabilities and adapt what they say to facilitate communication.

Additionally, listener-oriented adaptation may be driven by a process known as accommodation - a strategic adjustment of communicative behaviour by interlocutors to achieve a desired level of social distance (Giles, 1973; Giles \& Ogay, 2008; Shepard et al., 2001). Under this account, speakers may adapt their speech with the aim of 
affiliating themselves with or distancing themselves from a particular social group represented by their interlocutor. For example, Babel (2012) observed that the degree to which participants accommodated towards a model talker's vowels varied with their attractiveness rating of the talker as well as their perception of the talker's race. In a similar vein, M. Kim et al. (2011) found that interlocutors within the same regional dialect exhibited greater phonetic accommodation than interlocutors from different dialects or different native language backgrounds. The authors tentatively attribute these findings to a decision against adaptation by native speakers when faced with a heavily-accented nonnative interlocutor. Accommodation-based explanations could thus account not only for when speakers adapt to the linguistic forms used by their interlocutors (convergence), but also when they use different forms (divergence), with the goal of increasing or decreasing social distance. Accommodation may also influence syntactic adaptation: Weatherholtz, Campbell-Kibler, and Jaeger (2014) observed that participants were more likely to produce Prepositional Object (PO) or Double Object (DO) descriptions in line with a speaker they had recently heard if the speaker spoke with a standard variety of U.S. English or appeared to share the same political orientation as the participant. Interestingly, Weatherholtz et al. did not find any evidence for divergence from speakers who spoke with less standard varieties or presented with a different political stance, suggesting that the syntactic adaptation they observed was at least in part automatic, although interlocutor-specific social factors also played a role.

Regardless of whether listener-oriented adaptation is driven by audience design or accommodation mechanisms, both accounts predict that the extent of adaptation will be mediated by a speaker's inferences about their partner in the given moment. 
Therefore, we could expect to see different degrees of adaptation in native-native and native-nonnative interaction, based on evidence that speakers make different inferences about the linguistic knowledge, and therefore communicative needs, of a nonnative interlocutor (Ferguson, 1975).

\section{Native-nonnative interaction}

Inasmuch as speakers adjust what they say with their interlocutor in mind, they must first recognise the specific needs and knowledge of individual interlocutors. For example, a New Yorker might say "the Citicorp Center" when giving directions to a fellow New Yorker, but a different description (e.g. "the building with the slanted roof") with a tourist from a different city (cf. Isaacs \& Clark, 1987). Such considerations may be particularly relevant in native-nonnative interaction, where differences in cultural background or linguistic knowledge can increase the potential for miscommunication.

A long line of research has examined the types of linguistic adjustments that native speakers might make when interacting with nonnative speakers. Beyond Ferguson's (1975) characterisation of foreigner talk, a number of other researchers have highlighted features typical of speech directed at nonnative speakers. These adjustments may affect the acoustic properties of speech by native speakers, such as a slower speech rate, an expanded vowel space and a greater F0 range (Biersack et al., 2005; Scarborough et al., 2007; C. Smith, 2007; Uther et al., 2007), as well as the forms of their utterances, such as the omission of pronouns or greater use of comprehension checks (Braidi, 2002; Ferguson, 1975; Long, 1983). Another common observation is variation in grammaticality, where native speakers may opt for ungrammatical expressions to facilitate comprehension, for instance by replacing negative constructions with "no" (e.g. "no forget") or substituting expressions with lexically simpler ones (e.g. 
"today last day" for yesterday; Ferguson, 1975; Snow, Eeden, \& Muysken, 1981).

Moreover, speakers appear able to justify their modifications: Respondents in Ferguson (1975) provided comments in a questionnaire that reflected an underlying aim of simplifying their language use, such as "I dropped the 3rd pers. sing. $\underline{\text { s }}$ from 'works', hoping that the verb 'work' might be familiar to some of my hearers" and "I've used accusatives for the pronoun forms by way of simplification, i.e. fewer forms necessary in the total situation". Responses like these underscore a metalinguistic awareness about the degree of knowledge that a nonnative speaker may have of the language, providing support for an active, listener-oriented mechanism in nonnative-driven adaptation (cf. Costa, Pickering, \& Sorace, 2008).

Such strategic adjustments toward nonnative speakers are part of a broader phenomenon of audience-driven linguistic modification, alongside other special speech registers such as infant-/child-directed speech and pet-directed speech. Although studies highlight differences in the speech characteristics in different registers (Burnham, Kitamura, \& Vollmer-Conna, 2002; Knoll \& Uther, 2004; Uther et al., 2007; Xu, Burnham, Kitamura, \& Vollmer-Conna, 2013), the phenomenon appears to be robust across languages, cultures and gender (Andruski, Kuhl, \& Hayashi, 1999; Fernald et al., 1989; Kuhl et al., 1997; Prato-Previde, Fallani, \& Valsecchi, 2006), and in the case of infant-directed speech may even occur without conscious reflection (Combert, 1987; Papoušek, Papoušek, \& Symmes, 1991). Moreover, a notable observation across studies is the role of perceived linguistic competence as a driving force behind the degree of speech adjustment. For example, Uther et al. (2007) proposed that speakers used vowel hyperarticulation as a didactic device with both infants and foreigners, who were perceived as less capable linguistically compared to native English-speaking adults 
(cf. Kuhl et al., 1997). Similarly, Xu et al. (2013) observed an increasing trend in vowel hyperarticulation from dog-directed to parrot-directed to infant-directed speech, citing participants' expectations about the linguistic potential of their audience as an explanation. These findings support the idea of a didactic component to the linguistic modifications aimed at addressing the perceived needs of a target audience - a factor likely relevant in native-nonnative interactional exchanges (Uther et al., 2007).

\section{Adapting to one's partner in conversation}

Although the subject of nonnative-oriented adjustment has been studied extensively from a sociolinguistic perspective, much of early research relied on post-hoc methods such as native speakers' introspections (Ferguson, 1971, 1975; Meisel, 1976) or corpus-based analysis of unstructured conversation (Long, 1981; Snow et al., 1981). Later studies examining laboratory-based, task-oriented elicitations often made use of imagined situations rather than actual interaction (Biersack et al., 2005; Knoll, Scharrer, \& Costall, 2009; Papoušek \& Hwang, 1991). However, such methods may not be fully comparable with authentic communicative contexts: as Scarborough et al. (2007) observed, nonnative-directed speech with an imagined partner differed acoustically from that produced in the physical presence of an interlocutor.

A small number of studies have examined adaptation in face-to-face interaction. These have largely focussed on the acoustic-phonetic properties of nonnative-directed speech (Beebe, 1981; M. Kim et al., 2011). Ivanova, Costa, Pickering, and Branigan (2007) examined lexical adaptation in native Spanish speakers, and found that speakers were more likely to adopt dispreferred object names used by their partner when this partner was a nonnative rather than a fellow native speaker. Comparatively little work, though, has examined adaptation at the syntactic level and provided a systematic 
comparison of adaptation to native and nonnative interlocutors. Syntactic adaptation however may present a particularly interesting case given the grammatical adjustments that studies suggest are typical of nonnative directed speech (Ferguson, 1975; Snow et al., 1981; see above section).

Outside of research on native-nonnative interaction, empirical evidence shows that speakers frequently adapt towards the forms used by their conversation partners. An important demonstration of syntactic adaptation was provided by Branigan et al. (2000), who used a confederate scripting paradigm in which naive participants were paired with a confederate to take turns to describe and match pictures. Branigan et al. manipulated the form of the confederate's descriptions on prime trials: Half the primes were assigned Prepositional Object (PO) structures (e.g. "the pirate giving the banana to the doctor") and half were assigned Double Object (DO) structures (e.g. "the pirate giving the doctor the banana"). On subsequent target trials, participants were more likely to produce descriptions of the same syntactic form used by the confederate. This priming effect was amplified when the verb was repeated between prime and target trial (the "lexical boost" effect). Branigan et al.'s (2000) results have since been replicated in many studies, across a variety of syntactic structures and languages (e.g. Bernolet, Hartsuiker, \& Pickering, 2012; Branigan, Pickering, McLean, \& Cleland, 2007; Cai, Pickering, \& Branigan, 2012; Cleland \& Pickering, 2003; Hartsuiker et al., 2008, 2004; Raffray, Pickering, Cai, \& Branigan, 2014; Schoonbaert, Hartsuiker, \& Pickering, 2007; see Mahowald, James, Futrell, \& Gibson, 2016 for a meta-analysis). These findings demonstrate that grammatical encoding processes are sensitive to the linguistic behaviour of one's conversation partner - when given a message that can be formulated using more than one syntactic structure, speakers are likely to reuse the structure they 
have just heard their partner produce. This tendency towards repetition leads to syntactic coordination between speakers during dialogue.

Although Branigan et al. did not propose that such coordination arises as a result of any conscious negotiation between interlocutors, they pointed out that the magnitude of their effects were substantially greater than in other studies investigating priming within monologue tasks (e.g., Bock, 1986; Bock \& Loebell, 1990; Pickering \& Branigan, 1998). This difference may reflect the role of dialogue, in that the act of interacting with another speaker may engage adaptation processes in response to the communicative needs of the situation.

In this study, we use Branigan et al.'s (2000) confederate scripting technique to examine syntactic adaptation in dyadic dialogue. We focus on interaction between native and nonnative speakers of English. This is of particular interest since the communicative needs of an interaction may be especially relevant when one party is a nonnative speaker owing to difficulties of conversing in a second language, leading to increased pressure on the native speaker to adapt their language use accordingly (cf. Costa et al., 2008). Several recent studies in evolutionary linguistics have linked cross-linguistic differences in language complexity to the adaptation by native speakers to nonnatives (Atkinson, Smith, \& Kirby, 2018; Bentz \& Winter, 2014; Frank \& Smith, 2018; Lupyan \& Dale, 2010; Wray \& Grace, 2007), however direct experimental evidence of the relevant adaptive processes in natural languages is lacking. This study therefore allows us to focus on the local level of individuals interacting.

We report a series of experiments in which we investigated the degree of adaptation in native English speakers towards a nonnative conversation partner. In all experiments, a naive participant and a confederate took turns to describe pictures, and 
to match their partner's descriptions to pictures. Experiments 1-3 involved face-to-face interaction in the lab. In Experiment 1, confederates produced both Prepositional Object (PO) and Double Object (DO) prime sentences to describe ditransitive events. We tested the degree of adaptation and the lexical boost in participants' target descriptions, comparing interaction with a confederate who was either another native speaker or a nonnative speaker of English. In Experiment 2 we explored the effect of interacting with a less flexible interlocutor who only produced DO prime descriptions, some of which were ungrammatical (e.g. "The wizard donates the golfer the cake"). In addition, we used nonnative confederates with a stronger nonnative accent than in Experiment 1. Experiment 3 replicated the design of Experiment 1, looking only at interaction with a nonnative confederate who spoke with a strong nonnative accent. Experiments 4 and 5 were conducted online, using remote interaction with a (simulated) partner by utilising confederate recordings from Experiments 1-3. Experiment 4 replicated Experiment 1, looking at DO and PO priming with native and nonnative confederate recordings. Experiment 5 replicated Experiment 2, looking at grammatical and ungrammatical DO priming with native and nonnative confederate recordings.

Based on previous work examining syntactic adaptation between speakers in dyadic dialogue, we expect to find a basic priming effect of confederates' prime constructions on participants' target descriptions. If adaptation is influenced by listener-oriented mechanisms such as audience design or accommodation, we should expect a speaker-specific effect and hence a difference in the degree of adaptation with native and nonnative confederates. As predicted, we observed a priming effect across all experiments.

However, we observed differential adaptation with native and nonnative 
confederates only in Experiments 2 and 5, where confederates' syntactic behaviour was indicative of limited linguistic capabilities. The adaptation we observed also extended to the production of ungrammatical target DO constructions by our native participants. Unexpectedly, we saw a greater degree of adaptation to nonnative confederates in Experiment 2 but greater adaptation to native confederates in Experiment 5 . In other words, we saw a difference in the direction of adaptation between the lab-based and online versions of the experiment. We discuss possible reasons for this difference in the General Discussion.

\section{Experiment 1}

Experiment 1 examined the extent to which participants adapt their syntactic productions towards that of their conversation partner, comparing interaction between native speakers of English and a native or a nonnative confederate. Naive participants played a dialogue game with a confederate in which speakers alternated between describing a picture, and matching their partner's description to one of four pictures on their screen. We manipulated the form of confederates' descriptions on prime trials (Prepositional Object, PO, or Double Object, DO) as well as whether target descriptions involved the same verb or a different verb to that of the prime. We tested whether the form of participants' target descriptions (PO or DO) was dependent on the form of the confederate's prime description (PO or DO), the target verb parity (same verb or different verb) and whether the confederate was a native or a nonnative speaker of English. 


\section{Method}

Participants. Forty self-reported native English speakers between the ages of 18 and 35 took part in the experiment. Participants (20 each) were randomly paired with a confederate who was either a native speaker ( $n=4$ confederates) or a nonnative speaker ( $n=4$ confederates) of English. An additional six participants took part, but their data were excluded from analysis as they were a nonnative speaker of English (1) or reported being aware of the priming manipulation and/or the confederate's role during the debrief (5).

Participants were recruited from the University of Edinburgh careers service website and paid $£ 6$ to participate. Confederates were students at the same university (7) or a different university (1) and from the same age range as participants. The nonnative confederates spoke Hebrew (2), Dutch (1), and German (1) as their native language and additionally all had a good command of English. Confederates were paid at the same rate as participants per session.

Materials and design. Stimuli from the experiment came from a set of black and white line drawings consisting of twelve animate entities (artist, astronaut, chef, clown, cowboy, golfer, knight, pirate, prisoner, sailor, soldier, wizard) and six inanimate objects (apple, book, cake, cup, hat, vase). The experiment comprised 24 critical and 80 filler items. Each item consisted of a prime trial on which the confederate produced a description for an image on their screen, followed by a target trial on which the participant described an image on their screen.

On critical items, prime and target images depicted ditransitive events involving two animate entities — an agent and a beneficiary — and an inanimate theme. Target images additionally presented a present tense verb below the picture, which participants 


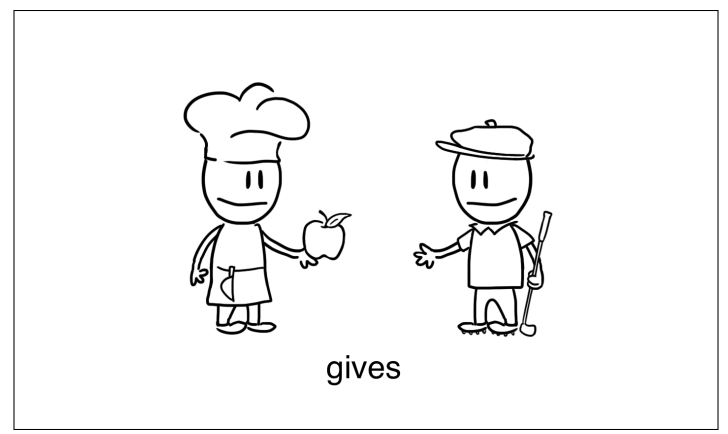

(a)

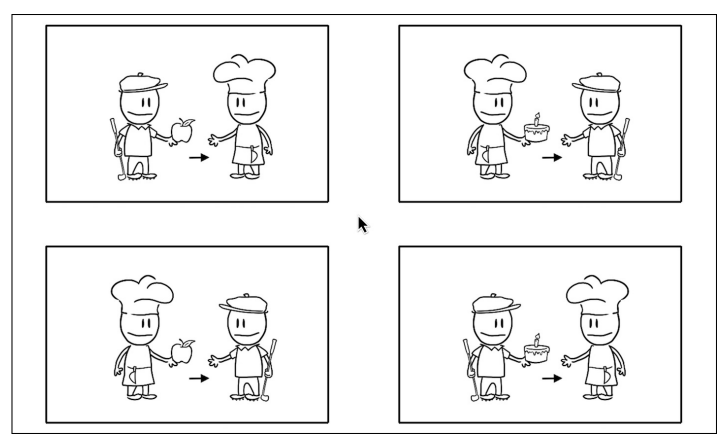

(b)

Figure 1. Example of a target picture (a) and corresponding match display (b)

were instructed to use in their descriptions (see Fig. 1a). Prime images presented the full description instead of the verb, which served as the confederate's script on the trial. Half of the confederate's prime sentences were assigned PO descriptions and the other half DO descriptions. Within each prime condition, half of the participant's target images presented the same verb as in the prime description, the other half presented a different verb. Hence the experiment utilised a 2 x 2 within-subjects design manipulating prime construction (PO/DO) and verb parity (same verb/different verb). Additionally, we manipulated confederate (native/nonnative) as a between-subjects factor. Table 1 presents an example of a prime description and target image in each within-subjects condition.

Agent, beneficiary and theme were selected randomly on each trial subject to the constraint that the agent and beneficiary were different entities, none of the three arguments were repeated across prime and target trials, and all entities and themes accurred an equal number of times in each within-subjects condition. The positions of agent and beneficiary were counterbalanced such that the agent appeared on the left in half of the images and on the right in the other half. Critical verbs were drawn from a list of six alternating dative verbs (brings, gives, hands, lends, offers, shows). Each verb 
Table 1

Example of a prime sentence and target image in each within-subjects condition in Experiment 1.

Prime construction Target verb parity Prime sentence

Target image

\begin{tabular}{|c|c|c|c|}
\hline $\mathrm{PO}$ & Same verb & The chef gives the apple to the golfer & pirate / artist / hat / gives \\
\hline $\mathrm{PO}$ & Different verb & The chef gives the apple to the golfer & pirate / artist / hat / brings \\
\hline DO & Same verb & The chef gives the golfer the apple & pirate / artist / hat / gives \\
\hline $\mathrm{DO}$ & Different verb & The chef gives the golfer the apple & pirate / artist / hat / brings \\
\hline
\end{tabular}

occurred once in a prime description and once in a target image in each within-subjects condition.

The experiment included 80 filler items, each also comprising a prime description by the confederate followed by a target description by the participant. Of the 80 filler prime trials, 36 described intransitive events, 36 described monotransitive events, and 8 described ditransitive events. Filler ditransitive primes used verbs drawn from a separate list of two alternating dative verbs (passes, loans), and were always produced as DO constructions. These were included to increase participants' exposure to the DO construction in order to encourage its production (cf. Ivanova, Pickering, McLean, Costa, \& Branigan, 2012, Experiment 1), based on the observation that participants tend to have a baseline preference to produce PO forms in dative elicitation tasks (e.g., Branigan et al., 2000; Conwell \& Demuth, 2007; Flett, Branigan, \& Pickering, 2013; Weatherholtz et al., 2014). ${ }^{3}$ Filler target images similarly depicted intransitive,

\footnotetext{
${ }^{3}$ This asymmetry is notable given evidence that the DO form occurs more frequently in natural language (Bresnan \& Ford, 2010; Gries, 2005) and emerges earlier in first language acquisition (Campbell \& Tomasello, 2001; Snyder, 2001; Snyder \& Stromswold, 1997). Explaining this asymmetry
} 
monotransitive and ditransitive events, in the same ratio as filler primes across the experiment. These were not always paired with a prime description of the same verb transitivity (hence a ditransitive filler prime description might, for instance, be followed by a monotransitive target image for the participant).

The experiment was presented as a communication game, where the task on each trial was to select the correct image from an array based on the description provided by the interlocutor. Match arrays presented four options in a two-by-two grid. One of these corresponded to the image being described; the remaining three were distractors (see Fig. 1b). Distractors systematically varied the entity(s), theme, and/or action depending on the transitivity of the verb: Ditransitive match distractors varied the agent, beneficiary and/or theme in each one of three possible arrays; monotransitive match distractors varied the agent, theme and/or verb in each one of three possible arrays; intransitive match distractors varied the agent and/or theme in each image. Table 1 provides example arrays for all three verb types. The positions of the target and three distractors within each match array was randomised.

Procedure. Participant and confederate were seated facing each other across a desk. The experiment was presented on separate 13" Apple Macintosh laptops. The confederate pretended to be a naive participant throughout the session until debrief. Prior to beginning, the experimenter conducted an oral language history questionnaire: Both interlocutors (starting with the confederate) were asked whether they were a native speaker of English, what age they started learning English from, and to provide a lies beyond the scope of our study; however Conwell and Demuth (2007) offer several explanations for why the preference may have emerged in children in their experiment, including discourse/pragmatic factors (e.g. whether the beneficiary was given or new to the discourse) or verb semantic biases (e.g. a preference to interpret novel verbs as locative rather than dative). 
Table 2

Example match arrays for ditransitive, monotransitive and intransitive descriptions.

\begin{tabular}{|c|c|c|}
\hline Array & Distractor manipulation & Example image \\
\hline \multicolumn{3}{|c|}{ Ditransitive (target image: chef gives golfer apple) } \\
\hline \multirow[t]{3}{*}{1} & roles swap & golfer gives chef apple \\
\hline & agent changes & prisoner gives golfer apple \\
\hline & agent changes \& roles swap & golfer gives prisoner apple \\
\hline \multirow[t]{3}{*}{2} & roles swap & golfer gives chef apple \\
\hline & beneficiary changes & chef gives prisoner apple \\
\hline & beneficiary changes \& roles swap & prisoner gives chef apple \\
\hline \multirow[t]{3}{*}{3} & roles swap & golfer gives chef apple \\
\hline & theme changes & chef gives golfer book \\
\hline & theme changes \& roles swap & golfer gives chef book \\
\hline \multicolumn{3}{|c|}{ Monotransitive (target image: chef stabs apple) } \\
\hline \multirow[t]{3}{*}{1} & agent changes & prisoner stabs apple \\
\hline & theme changes & chef stabs book \\
\hline & agent \& theme change & prisoner stabs book \\
\hline \multirow[t]{3}{*}{2} & agent changes & prisoner stabs apple \\
\hline & verb changes & chef drops apple \\
\hline & agent \& verb change & prisoner drops apple \\
\hline \multirow[t]{3}{*}{3} & theme changes & chef stabs book \\
\hline & verb changes & chef drops apple \\
\hline & theme \& verb change & chef drops book \\
\hline \multicolumn{3}{|c|}{ Intransitive (target image: chef cries) } \\
\hline \multirow[t]{3}{*}{1} & agent changes & prisoner cries \\
\hline & verb changes & chef sings \\
\hline & agent \& verb change & prisoner sings \\
\hline
\end{tabular}


self-rating of their English proficiency on a scale of 1 (least fluent) to 7 (native-like). Non-native confederates were instructed to state that they started learning English at age 11 and to provide a self-rated proficiency of 4; native confederates were instructed to state that they started learning English from birth and to provide a self-rated proficiency of 7 .

Participant and confederate were told the task involved taking turns to describe a picture and to match their partner's description to the correct picture (out of four options). Sessions began with the confederate describing and the participant matching. Trial progression on both laptops was triggered when the matcher clicked on an image, alternating between description and match trials. No feedback was provided on match trials. Participant and confederate descriptions were recorded on a trial-by-trial basis by the experiment script on each laptop. The order of presentation of items was randomised for each dyad, with the experiment always beginning with at least three filler items.

After each session the participant was debriefed, during which they were orally questioned about their awareness of the priming manipulation and the confederate's role in the experiment.

Coding and analysis. Participants' descriptions were transcribed and each trial was coded as PO, DO or Other. Descriptions were coded as PO if the theme immediately followed the verb and was followed by the preposition to and the beneficiary, and as DO if the beneficiary immediately followed the verb and was followed by the theme. All other descriptions were coded as Other. These included semantically anomalous constructions (e.g. "The chef gives the apple the artist") and cases of ambiguity such as when the participant restarted or repeated their description 
using a different construction. Descriptions coded as Other were excluded from the final dataset used for analysis.

The data were analysed in R Version 3.5.0 (R Core Team, 2016) using the lme4 package (Bates, Maechler, Bolker, \& Walker, 2014). Logistic mixed effects regression was used to model the outcome variable of whether or not the participant produced a DO description on each trial. To check whether participants' behaviour differed significantly across confederates in each confederate condition, we ran a preliminary analysis on the effect of confederate ID on participants' descriptions. Separate models were constructed for the native and the nonnative confederate conditions Models included the sole predictor of confederate ID (sum coded) and by-participant random intercepts. This analysis showed that there was no effect of confederate ID on participants' descriptions (all $p>.1$ ). To explore the degree of adaptation exhibited by participants, we modelled the outcome variable taking prime construction (PO vs. DO; mean centred), target verb parity (same verb vs. different verb; mean-centred) and confederate (native vs. nonnative; dummy coded, reference level native) as fixed effects. The model included by-participant random intercepts and slopes for all within-subject manipulations, and random intercepts for target verb and confederate ID.

\section{Results}

Of the 960 target descriptions produced, 617 (64.3\%) were coded as PO, 340 (35.4\%) were coded as DO, and $3(0.3 \%)$ were coded as other. Figure 2 shows the mean percentages of DO descriptions out of all valid target descriptions recorded in each condition. 


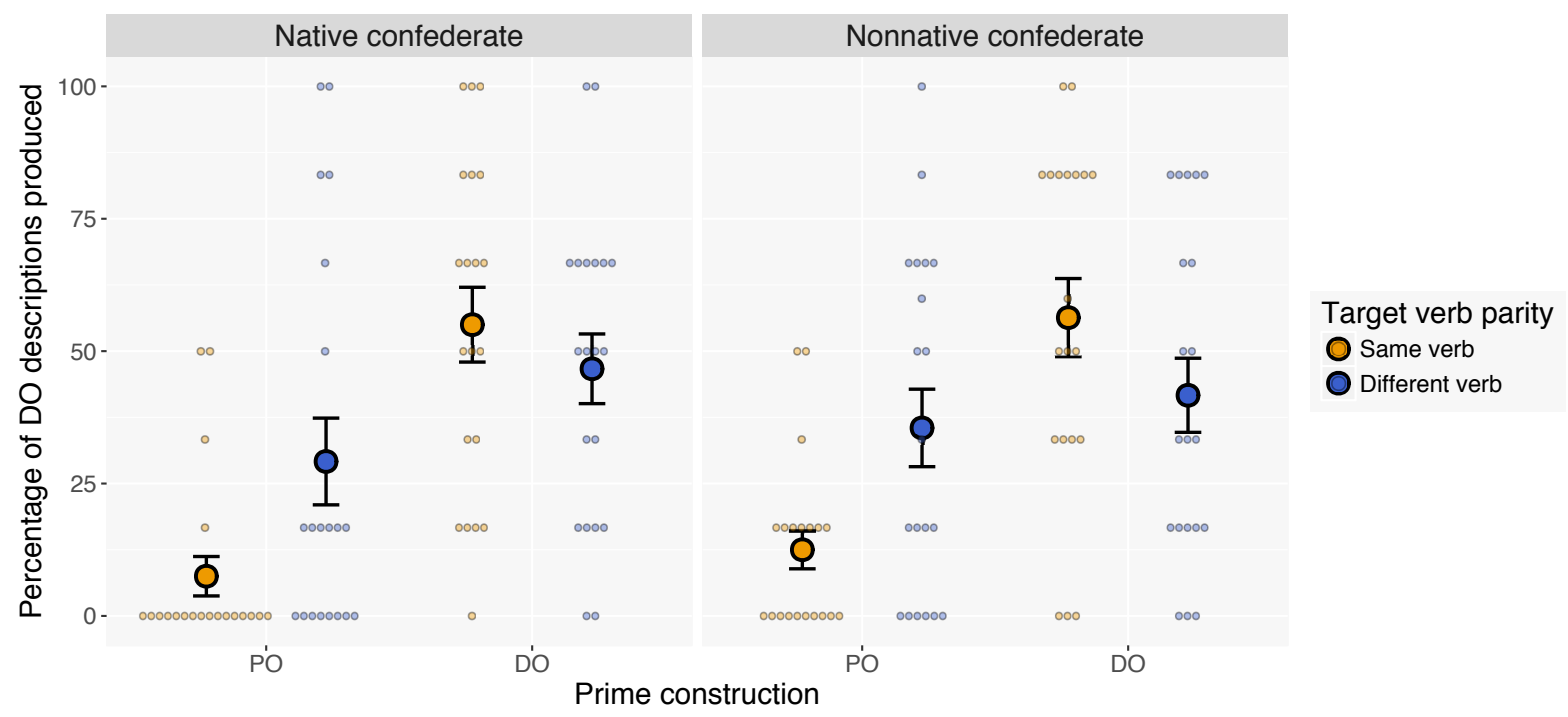

Figure 2. Mean percentages of DO descriptions produced in each condition in

Experiment 1. Percentages were calculated out of the total number of valid descriptions (i.e. all descriptions coded as PO or DO) recorded in each condition. Error bars represent \pm 1 standard error of by-participant means. Dots represent individual participant means.

There were main effects of prime construction and target verb parity: Participants were more likely to produce a DO description following a DO prime from the confederate, $\beta=2.75, S E=0.44, p<.001$, as well as when the target verb was different from the prime verb, $\beta=0.92, S E=0.34, p=.006 .{ }^{4}$ There was additionally a lexical boost effect, as indicated by a prime construction by target verb type interaction: Participants were less likely to produce a DO utterance following a DO prime when the target verb was different to the prime verb, $\beta=-2.75, S E=0.66$, $p<.001$. None of the other predictors nor their interactions were significant. There was

\footnotetext{
${ }^{4}$ Note that there was no reason to expect more DOs with the same or a different target verb regardless of prime construction. We do not have an explanation for this finding; however we do not discuss it further as it not central to our conclusions.
} 
a marginal prime construction by confederate interaction: Participants were marginally less likely to produce a DO description following a DO prime if they were interacting with a nonnative confederate, $\beta=-0.87, S E=0.51, p=.09$.

\section{Discussion}

The results from Experiment 1 provide evidence that speakers adapt towards the syntactic forms used by their conversation partner. DO primes from the confederate yielded more DO descriptions from the participant than PO descriptions, suggesting that the structure participants chose was influenced by that which they heard the confederate produce on the immediately preceding trial. This effect was enhanced by repetition of the verb between the prime and target trial. These results replicate those of Branigan et al. (2000), and are consistent with those of other studies employing confederate scripting to test syntactic priming in dialogue (e.g., Cai et al., 2012; Cleland \& Pickering, 2003; Hartsuiker et al., 2008, 2004).

Our results show that priming of the dative construction during dialogue extends to native-nonnative interaction-specifically, native speakers can be primed by the forms used by a nonnative interlocutor. However, this effect was similar in magnitude to that of interaction with another native speaker of English. In other words, native speakers did not exhibit a greater tendency towards adaptation when interacting with a nonnative speaker; in fact, they were marginally more likely to adapt towards the forms used by a native confederate. The fact that we find no evidence for greater adaptation with nonnatives is at odds with Branigan et al. (2011, Experiment 5), who found higher levels of adaptation with a computer system perceived to be less capable linguistically, suggesting that adaptation is mediated by a speaker's considerations about their partner's communicative capabilities. There are a few potential explanations for this 
difference in results.

Firstly, Branigan et al. (2011) investigated lexical-based adaptation, looking at participants' choice of referring expressions in a picture-naming task, whereas our experiment focussed on syntactic adaptation. It is possible that adaptation driven by beliefs about one's interlocutor may not extend to the syntactic level. Alternatively, such beliefs may be more influential during interaction with a computer compared to another human. This is consistent with Branigan et al.'s finding that participants showed a stronger tendency to adapt towards a partner they believed to be a computer than a human.

A second possibility is that native speakers are equally likely to adapt towards the syntactic forms used by a native and a nonnative interlocutor. This, however, seems unlikely given studies which suggest a greater degree of linguistic modification during interaction with nonnative interlocutors, for other properties of speech such as vowel articulation or speech rate (e.g., Biersack et al., 2005; Uther et al., 2007). While these findings do not demonstrate explicit adaptation towards the characteristics of nonnative speech, they nevertheless highlight measurable differences between speech directed at native and nonnative interlocutors.

Finally, it could be that the linguistic behaviour of our nonnative confederates was too similar to that of our native confederates. As mentioned earlier, the nonnative confederates we employed would all be considered advanced speakers of English, and therefore may have been less likely to elicit the ungrammatical or unnatural forms observed in studies on nonnative-directed speech such as Ferguson (1975) or Bortfeld and Brennan (1997). If adaptation is mediated by inferences about an interlocutor's linguistic knowledge or capabilities, a lack of any indication of communicative difficulty 
from nonnative confederates may have led to similar behaviour in participants across the two conditions. Moreover, the experimental task provided clear evidence that confederates were familiar with both the PO and DO constructions - they used both interchangeably — reducing the need for participants to consider using one form over the other. Therefore any adaptation we observed may have been driven solely by unconscious priming processes rather than any perceived need to adjust based on their partner's apparent linguistic knowledge or communicative needs. We address this possibility in Experiment 2.

\section{Experiment 2}

Our intuition was that the lack of any differences in the degree of adaptation towards native and nonnative interlocutors in Experiment 1 was due to the evident linguistic competence of the nonnative confederates in the experiment. Thus in Experiment 2, we explored the effect of interacting with an interlocutor whose syntactic behaviour was more inflexible and unnatural. We induced this impression through several changes to the experiment design:

1. Confederates produced ditransitive prime descriptions exclusively in the DO construction, half of which were ungrammatical (involving a non-alternating verb; e.g. "The chef reveals the golfer the apple"),

2. The experiment began with a block of 20 filler items which included several ditransitive prime descriptions by the confederate, giving the participant some time to note the confederate's unusual use of the DO construction,

3. A short temporal delay was implemented at the start of both description and match trials for the confederate, to simulate difficulties in production and 
comprehension.

In addition, we used nonnative confederates who (impressionistically) spoke English with a more noticably nonnative accent.

We hypothesised that these changes would generate an inference about the confederate's linguistic knowledge, increasing the pressure on participants to adapt based on their perception of their partner's communicative needs. Importantly, we expected these inferences to differ depending on whether the confederate was a native or a nonnative speaker. Recent research on accent perception demonstrates that native listeners respond differently to erroneous sentences produced by a native compared to a nonnative speaker. Syntactic violations such as gender disagreements that result in a classical P600 effect in native speech elicit no P600 effect when the same violations are produced by a nonnative speaker (Hanulíková, Van Alphen, Van Goch, \& Weber, 2012). Hanulíková et al. attribute this to different expectations that listeners hold about grammatical errors from native and nonnative speakers - while grammatical wellformedness may be the default expectation with native speech, listeners may expect more errors from nonnative speakers, resulting in a greater tolerance to such errors. Gibson et al. (2017) similarly propose that native listeners expect a higher error rate in nonnative-accented speech. Participants in their study were more likely to interpret anomalous sentences such as "The mother gave the candle the daughter" plausibly (e.g. by assuming the daughter to be the intended recipient) when produced by a nonnative-accented speaker. Gibson et al. suggest that nonnative speakers are more likely to be perceived as syntactically unstable, motivating listeners to reinterpret utterances that would otherwise be regarded as incorrect or implausible in native speech. Accent-based modulations have also been observed in the processing of disfluent 
speech: Listeners' biases towards expecting low frequency referents (e.g. "sewing machine" as opposed to "hand") following a disfluency such as an "uh" disappeared when the utterance was produced by a nonnative speaker (Bosker, Quené, Sanders, \& De Jong, 2014). Bosker et al. attributed this to native listeners' adjustments to the predictive properties of disfluencies with respect to their inferred proficiency of a nonnative speaker. In short, native listeners appear to make stereotype-dependent inferences in response to anomalous or erroneous utterances on the basis of the speaker's accent. Consequently, we expected that our participants' perception of the confederate's nativeness/nonnativeness in Experiment 2 would similarly modulate their inferences about their partner, influencing the degree of adaptation with native and nonnative confederates.

As in Experiment 1, participants were paired with a confederate and alternated between describing and matching pictures. The absence of PO primes necessitated a slightly different approach to analysis: We examined whether the form of participants' target descriptions was dependent on the grammaticality of the confederate's prime description (grammatical or ungrammatical), the type of verb on target trials (alternating or non-alternating), the target verb parity (same verb or different verb), and the confederate's nativeness (native or non-native). In particular, we were interested in whether participants would produce ungrammatical DO constructions following an ungrammatical prime from the confederate, and whether this effect would differ across interaction with native and nonnative confederates.

\section{Method}

Participants. Forty self-reported native English speakers between the ages of 18 and 35 were paid $£ 6$ to take part. Participants (20 each) were randomly paired with 
a confederate who was a native speaker ( $n=2$ confederates) or a nonnative speaker ( $n=2$ confederates) of English. An additional three participants took part but their data were excluded from analysis as they reported being aware of the priming manipulation and/or the confederate's role during the debrief.

Participants were recruited from the University of Edinburgh careers service website. None had taken part in Experiment 1. Confederates were from the same age range as participants, and were students at the same university (3) or attending a private English language course (1). The nonnative confederates spoke Mandarin Chinese (1) and Italian (1) as their native language. Additionally, they both spoke English with a noticeable nonnative accent. Confederates were paid at the same rate as participants.

Materials and design. The materials were the same as those used in Experiment 1, with the following exceptions.

Firstly, we introduced non-alternating verbs to the set of critical verbs. Hence, critical verbs included four alternating (gives, hands, lends, shows) and four non-alternating (displays, donates, reveals, restores) dative verbs; alternating verbs can occur with $\mathrm{PO}$ or DO in native English, non-alternating verbs only occur with PO. The verbs were chosen based on a pre-test to obtain grammaticality ratings for alternating and non-alternating verbs in the $\mathrm{PO}$ and $\mathrm{DO}$ construction. In the pre-test, 16 additional participants were asked to rate 80 sentences on a scale of 1 (not grammatical at all) to 7 (perfectly grammatical). The sentences included 16 ditransitive sentences with alternating verbs (eight PO; eight DO), 24 ditransitive sentences with non-alternating verbs (12 PO; 12 DO), and 40 filler sentences (12 monotransitive; 12 intransitive sentences; 16 semantically anomalous). Table 3 summarises the results from 
the pre-test. We selected alternating verbs that scored the highest mean ratings and non-alternating verbs that scored the lowest mean ratings for the DO construction as critical verbs.

Table 3

Mean grammaticality ratings by sentence construction in the pre-test. Standard errors in parentheses.

\begin{tabular}{lll} 
Sentence construction & Example sentence & Mean rating \\
\hline Ditransitive (alternating verb), DO & The chef gives the golfer the apple & $6.33(.13)$ \\
Ditransitive (alternating verb), PO & The chef gives the apple to the golfer & $6.92(.04)$ \\
Ditransitive (non-alternating verb), DO & The chef reveals the golfer the apple & $2.87(.15)$ \\
Ditransitive (non-alternating verb), PO & The chef reveals the apple to the golfer & $6.05(.13)$ \\
Monotransitive & The chef stabs the apple & $6.86(.04)$ \\
Intransitive & The chef cries & $6.69(.07)$ \\
Semantically anomalous & The clown disappears the hat & $2.46(.12)$ \\
\hline
\end{tabular}

There was no longer a prime construction manipulation since all prime descriptions were produced as DO constructions. Half of the primes were grammatical (involving an alternating verb) and the other half ungrammatical (involving a non-alternating verb). Within each prime condition, half of the target verbs that participants saw were alternating, and the other half non-alternating. Additionally, in the grammatical prime-alternating target and ungrammatical prime-non-alternating target conditions we manipulated the target verb parity-half the items presented the same verb across prime and target trials and the other half presented a different verb. Table 4 summarises the within-subjects design, with examples of a prime description and target image in each condition. In addition, we manipulated confederate 
(native/nonnative) as a between-subjects factor.

Table 4

Example of a prime sentence and target image in each within-subjects condition in Experiment 2.

\begin{tabular}{|c|c|c|c|c|}
\hline Prime grammaticality & Target verb type & Target verb parity & Prime sentence & Target image \\
\hline \multirow{4}{*}{ Grammatical } & \multirow{2}{*}{ Alternating } & Same verb & The chef gives the golfer the apple & pirate / artist / hat / gives \\
\hline & & Different verb & The chef gives the golfer the apple & pirate / artist / hat / brings \\
\hline & \multirow{2}{*}{ Non-alternating } & Same verb & NA & \\
\hline & & Different verb & The chef gives the golfer the apple & pirate / artist / hat / reveals \\
\hline \multirow{4}{*}{ Ungrammatical } & \multirow{2}{*}{ Alternating } & Same verb & NA & \\
\hline & & Different verb & The chef reveals the golfer the apple & pirate / artist / hat / gives \\
\hline & \multirow{2}{*}{ Non-alternating } & Same verb & The chef reveals the golfer the apple & pirate / artist / hat / reveals \\
\hline & & Different verb & The chef reveals the golfer the apple & pirate / artist / hat / donates \\
\hline
\end{tabular}

The 80 filler items now consisted of 16 ditransitive, 32 monotransitive and 32 intransitive events. The number of ditransitive fillers was increased to accommodate the addition of non-alternating verbs to the experiment. Filler ditransitive verbs were drawn from a list separate to that of critical verbs and consisted of two alternating (passes, loans) and two non-alternating (conveys, entrusts) verbs. As in Experiment 1, filler items did not always involve the same verb transitivity across prime and target trials.

Finally, the experiment began with a block of 20 filler items, consisting of eight ditransitive (four alternating; four non-alternating), six monotransitive and six intransitive filler prime descriptions. This was introduced to increase participants' early exposure to DO primes, with the aim of generating the inference that the confederate had a preference for this construction at the expense of grammaticality. During this block, the participant was only presented with monotransitive and intransitive target trials (10 each) to reduce any potential effects of self-priming on ditransitive sentences 
(see Reitter \& Moore, 2006; M. Smith \& Wheeldon, 2001). The rest of the experiment presented the 24 critical items intermingled amongst the remaining 60 filler trials. The order of presentation of items was randomised for each participant with the constraint that critical items were separated by at least one filler item.

Procedure. The procedure was the same as Experiment 1 except for the introduction of a temporal delay at the start of each trial for the confederate: On description trials, the confederate's screen remained blank for a duration $(2,000 \mathrm{~ms}$ on critical trials; randomly variable between 1,000-2,500 ms on filler trials) before the image and sentence were displayed; on match trials, the array was shown for a random duration (between 2,000-3,000 ms) before the mouse pointer appeared at the screen centre. The timing of trial progression remained unchanged for the participant.

Coding and analysis. Transcription and coding of participants' descriptions were the same as in Experiment 1. The data were analysed using logistic mixed effects regression. The dependent variable was whether or not the participant produced a DO description on each trial. To check whether participants' behaviour differed significantly across confederates within each confederate condition (native or nonnative), we ran a preliminary analysis on the effect of confederate ID (sum coded) on participants' descriptions, including by-participant random intercepts in the model. This analysis indicated an effect of confederate ID for the nonnative confederate condition: Participants were more likely to produce a DO description when interacting with one of our two nonnative confederates, $\beta=0.76, S E=0.29, p=.01$. We discuss the implications of this effect in the Discussion.

To explore the degree of adaptation in participants, we modelled the effects of prime grammaticality (grammatical vs. ungrammatical; mean centred), target verb type 
(alternating vs. non-alternating; mean centred), target verb parity (same verb vs. different verb; mean centred), and confederate (native vs. nonnative; dummy coded, reference level native) on the dependent variable. The model included by-participant random intercepts and slopes for all within-subject manipulations, and random intercepts for target verb and confederate ID.

\section{Results}

Of the 960 target descriptions produced, 728 (75.8\%) were coded as PO, 217 $(22.6 \%)$ were coded as DO, and $15(1.6 \%)$ were coded as other. Notably, the 217 DO descriptions included 32 (14.7\% of all DOs produced) ungrammatical constructions involving non-alternating verbs. Figure 3 reports the mean percentages of DO descriptions out of all valid target descriptions recorded in each condition.

There were main effects of target verb type and target verb parity: Participants were less likely to produce a DO description with non-alternating target verbs, $\beta=-3.07, S E=0.91, p<.001$, as well as when the target verb was different from the prime verb, $\beta=-1.20, S E=0.54, p=.03^{5}$. There was additionally a main effect of confederate indicating that participants were more likely to produce a DO description when interacting with a nonnative confederate than a native confederate, $\beta=1.05$, $S E=0.52, p=.04$. None of the other predictors nor their interactions were significant (all $p>.1$ ). There was a marginal three-way interaction between prime type, target verb parity and confederate: Participants were marginally less likely to produce a DO description following an ungrammatical prime when the target verb was different to the prime verb, with this difference being greater when interacing with a nonnative

\footnotetext{
${ }^{5}$ As in Experiment 1, there was no reason to expect an effect of target verb parity on participants' rate of DO productions; however we do not discuss this effect as it is not central to our conclusions
} 


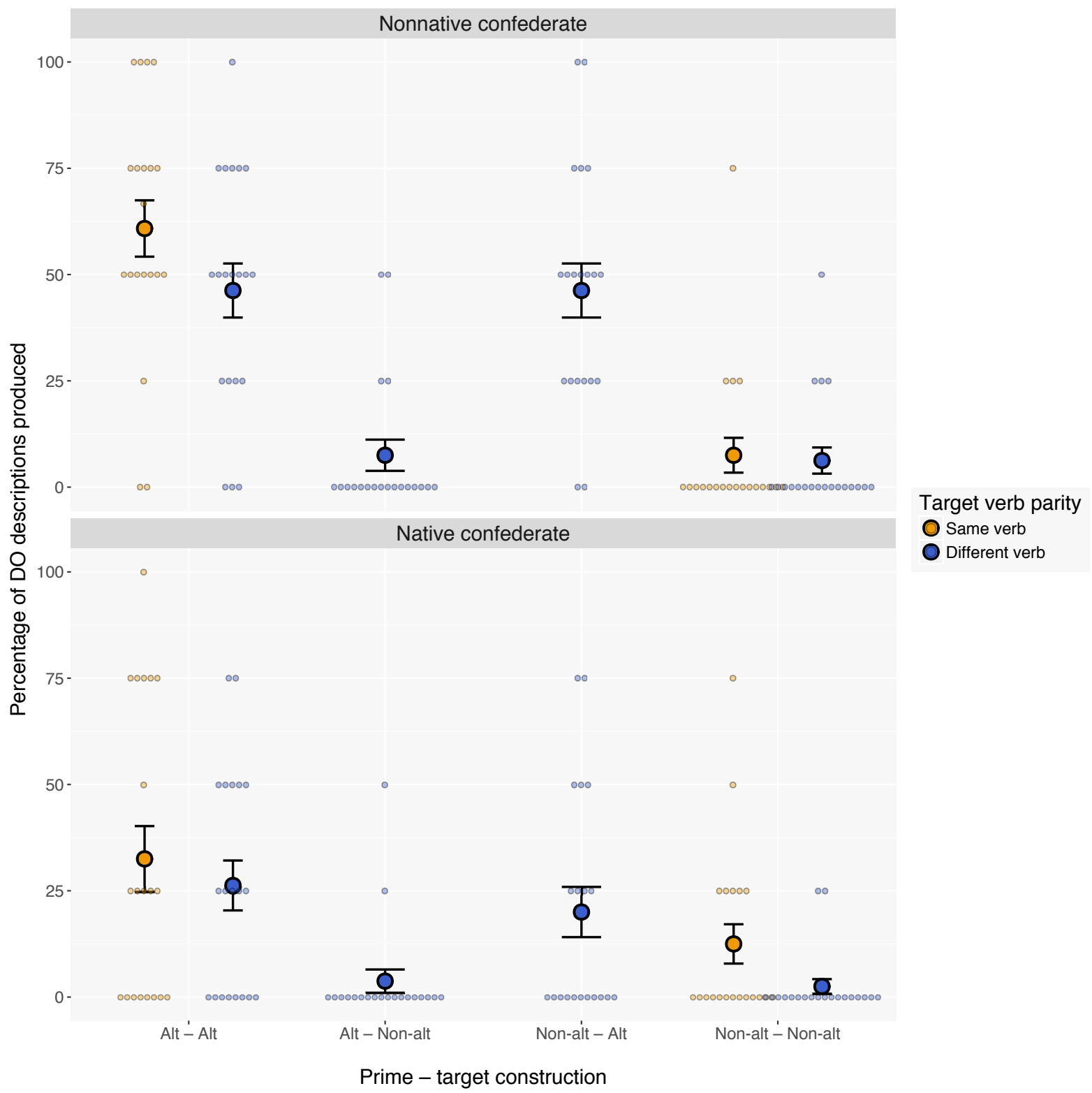

Figure 3. Mean percentages of DO descriptions produced in each condition in Experiment 2. Percentages were calculated out of the total number of valid descriptions (i.e. all descriptions coded as PO or DO) recorded in each condition. Error bars represent \pm 1 standard error of by-participant means. Dots represent individual participant means. The $\mathrm{x}$-axis labels denote the verbs used by the confederate and the participant in the prime and target trials respectively, e.g. Alt-Alt indicates that the both the confederate and the participant produced descriptions involving an alternating verb which permits either a PO or a DO construction. All DO descriptions produced by participants in the non-alternating target conditions were ungrammatical. 
compared to a native confederate, $\beta=2.30, S E=1.27, p=.07$. This reflects that participants were more likely to adapt to native confederates' ungrammatical constructions that were followed by the same target verb.

\section{Discussion}

Experiment 2 explored adaptation in speakers during interaction with a less flexible partner, and tested whether the priming of DO datives would extend to ungrammatical sentences. To that end, we modified the syntactic behaviour of confederates such that they only produced DO prime descriptions, half of which were ungrammatical. We also used more strongly accented nonnative confederates than in Experiment 1. We hypothesised that collectively, these changes would elicit an inference in speakers about their partner's communicative needs based on their apparent linguistic ability.

Despite being exposed to DO primes exclusively, participants still produced more PO than DO target descriptions across the experiment (75.8\% vs. $22.6 \%)$. This is not entirely surprising given the inclusion of non-alternating dative verbs, which are only compatible with the PO construction, in the experiment's design. Consequently, we observed a large effect of target verb type such that participants produced more DO descriptions with alternating than non-alternating target verbs.

However, it is notable that of the DO descriptions recorded, $15 \%$ were ungrammatical target constructions such as "The chef reveals the sailor the apple". This is suggests that the priming of DO datives can extend to ungrammatical sentences with non-alternating verbs. This finding is in line with Ivanova et al. (2012), who also showed that speakers can be primed to produce ungrammatical DO sentences with non-alternating verbs, although only when the preceding prime sentence was similarly 
ungrammatical and when they shared the same verb as the target verb (but not when the target verb differed). Ivanova et al. (2012) investigated priming within a monologue task in which participants read prime sentences out loud and produced target descriptions with no interlocutor present. Extending these findings, we demonstrate that the priming of such ungrammatical constructions can occur from comprehension (of another speaker's utterances) to production.

Experiment 2 also showed an effect of confederate, with more DO descriptions during interaction with nonnative compared to native confederates. This suggests that a priming-based account, which predicts that adaptation should not depend on partner-specific characteristics or behaviour, is alone insufficient to explain the pattern of adaptation we observed. Rather, our results point towards an active, listener-oriented component to adaptation in which speakers inferred about their partner's linguistic knowledge and communicative needs, and adjusted their language use accordingly. This finding is consistent with previous work on lexical adaptation, which found that speakers' tendency to adopt a partner's naming preferences depended on their beliefs about their partner's linguistic capabilities (Branigan et al., 2011).

Such a listener-oriented account would also explain the difference in results between Experiments 1 and 2. In Experiment 1, where confederates provided no indication of any particular communicative need, we observed similar levels of adaptation towards native and nonnative interlocutors. It was only in Experiment 2, where confederates' behaviour indicated limited linguistic proficiency, when differential adaptation emerged. Together, these results provide support for listener-oriented adaptation, and suggests that such adaptation may occur only when the communicative situation elicits an inference about a partner's linguistic needs or knowledege. 
Why then did speakers not similarly adapt towards the syntactic forms of native interlocutors in Experiment 2? If interlocutor-specific adaptation was driven solely by consideration of a partner's knowledge and needs, one might still expect to see similar levels of adaptation to natives and nonnatives in Experiment 2, given confederates all exhibited the same syntactic inflexibility. Instead, we observed a difference suggesting that speakers' inferences about their partner's linguistic proficiency were modulated by their perception of their partner as a native or nonnative speaker. This supports existing research demonstrating that native listeners exhibit a different response to erroneous speech produced by native and nonnative speakers (Bosker et al., 2014; Gibson et al., 2017; Hanulíková et al., 2012). In particular, listeners appear to adjust their expectations to permit a larger degree of error with nonnative speakers. Analogously, speakers in Experiment 2 may have been more accepting of the ungrammatical DO forms produced by nonnative than native confederates, increasing their own production of DOs with nonnative partners to facilitate communication.

However, our interpretation of results here faces two limitations. Firstly, we made several changes between Experiments 1 and 2 which complicate a direct comparison - specifically, we modified confederates' behaviour to simulate syntactic inflexibility, and also employed different confederates (in particular nonnative speakers who spoke with a more noticeable nonnative accent). While these changes appear to have been successful at inducing an inference about confederates' knowledge and needs, they introduce more than one potential factor to attribute this inference to. The differential adaptation in Experiment 2 could thus be due to a linguistic component (confederates' rigid production of DO constructions), a social component (implicit attitudes towards nonnative-accented speech), or a combination of the two. Secondly, 
the effect of confederate we observed was statistically much weaker in comparison with the robust effect of target verb type. The large standard errors also indicate a considerable degree of individual variation in terms of tendency to adapt.

Given these limitations, we decided to conduct two follow-ups. In the first, we conducted a third experiment to examine the effect of the degree of accentedness on adaptation. Experiment 2 revealed an effect of confederate ID indicating that participants were more likely to produce DO descriptions with one of the two nonnative confederates. Anecdotally, we note that this confederate spoke with a more pronounced nonnative accent. This may highlight the role of degree of accentedness on participants' inferences, although it does not rule out the contribution of confederates' syntactic behaviour. Thus, Experiment 3 was designed to tease apart these two by focussing on accent alone. In the second follow-up, we conducted two online experiments replicating the design of Experiments 1 and 2 respectively with a larger sample size. These were intended to establish if we could replicate the same pattern of adaptation with a larger sample.

\section{Experiment 3}

Having established that speakers adapt differently to native and nonnative interlocutors based on an inference about their partner's communicative needs, and that this inference may be driven by their partner's syntactic behaviour or the strength of their accent, in Experiment 3 we aimed to isolate the potential effect of a strongly-accented nonnative interlocutor on adaptation. The experiment was a replication of the nonnative condition of Experiment 1, with a confederate who spoke English with a more noticeable nonnative accent. Thus, Experiment 3 was intended to serve as a direct comparison to Experiment 1, which employed nonnative confederates 
who all spoke with near-native accents. Experiment 3's confederate was the same nonnative confederate from Experiment 2 who participants were significantly more likely to produce DO descriptions with. We reasoned that this confederate was the most likely candidate from our pool of confederates to elicit an inference from speakers based on accent alone.

If the greater adaptation we observed with nonnative interlocutors in Experiment 2 was due to the confederates' degree of accentedness rather than their inflexible production of DO constructions, we should expect more adaptation in Experiment 3 compared to both the native and nonnative conditions in Experiment 1. Alternatively, if the differential adaptation we observed was driven by the confederates' syntactic behaviour rather than their accent, we should expect similar levels of adaptation in Experiments 1 and 3 .

\section{Method}

This was identical to Experiment 1 except for the omission of the confederate manipulation; all participants interacted with a nonnative confederate. Twenty self-reported native speakers of English between 18 and 35 years of age who had not taken part in Experiments 1 or 2 were paid $£ 6$ to participate. The confederate was a native speaker of Mandarin Chinese and spoke English with a noticeable nonnative accent. Data from an additional two participants who reported being aware of the confederate's role during debrief were excluded from analysis.

Coding and analysis. Transcription and coding of participants' descriptions were the same as in Experiment 1. The data were analysed using logistic mixed effects regression. We first analyse the data from Experiment 3 in its own right, then proceed to the comparison with data from Experiment 1 (described in the following section). To 
evaluate the degree of adaptation in participants in Experiment 3, we modelled the effects of prime construction (PO vs. DO; mean-centred) and target verb parity (same verb vs. different verb; mean-centred) on the outcome variable of whether or not the participant produced a DO description on each trial. The model included by-participant random intercepts and slopes for all within-subject manipulations, and random intercepts for target verb.

\section{Results}

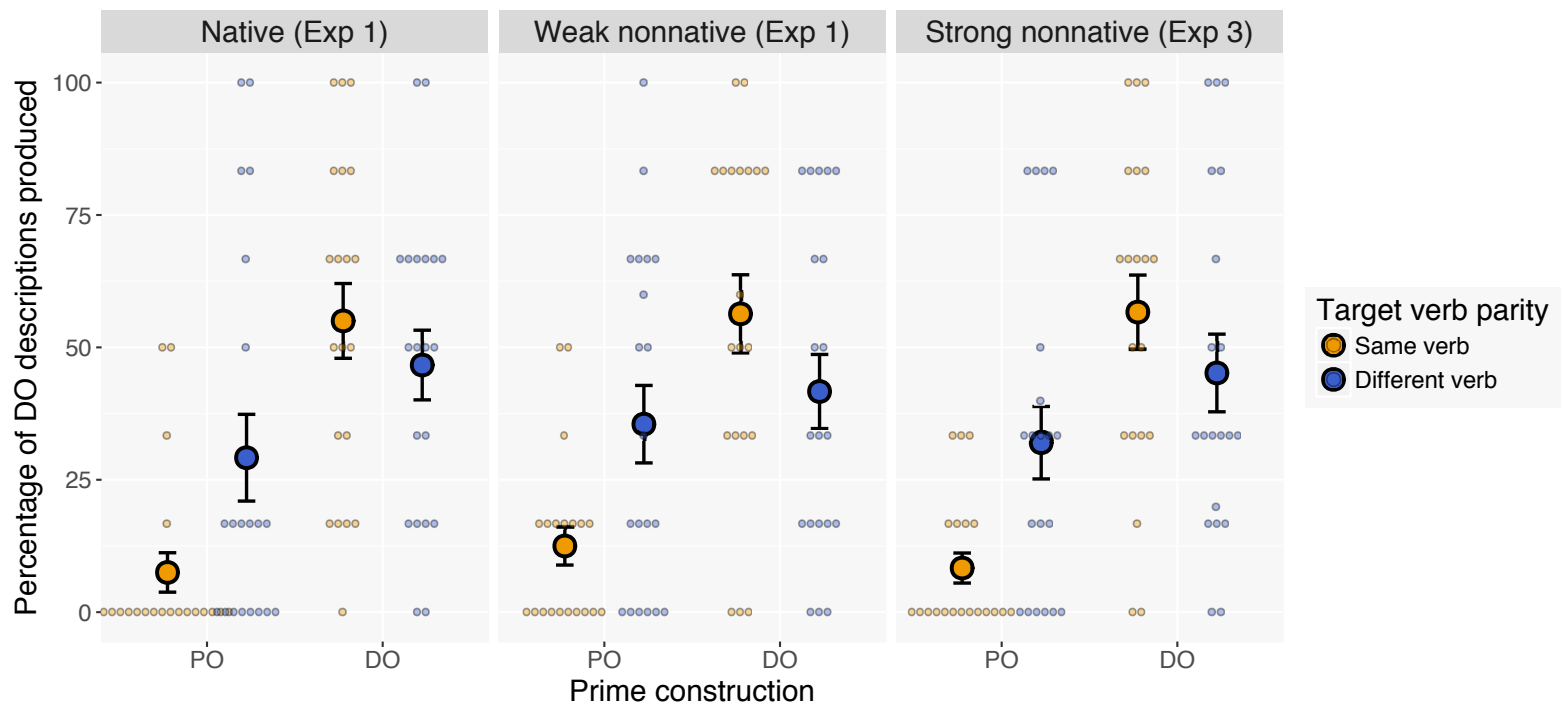

Figure 4. Mean percentages of DO descriptions produced in each accent condition in Experiments 1 (panels 1 and 2) and 3 (panel 3). Percentages were calculated out of the total number of valid descriptions (i.e. all descriptions coded as PO or DO) recorded in each condition. Error bars represent \pm 1 standard error of by-participant means. Dots represent individual participant means.

Of the 480 target descriptions produced, 307 (64.0\%) were coded as PO, 170 (35.4\%) were coded as DO, and $3(0.6 \%)$ were coded as other. Figure 4 panel 3 shows the mean percentages of DO descriptions out of all valid target descriptions produced 
by participants.

There were main effects of prime type and target verb parity: Participants were more likely to produce a DO description following a DO prime from the confederate, $\beta=2.17, S E=0.36, p<.001$, as well as when the target verb was different from the prime verb, $\beta=0.72, S E=0.32, p=.03$. There was additionally a lexical boost effect, as indicated by a prime construction by target verb parity interaction: Participants were less likely to produce a DO description following a DO prime when the target verb was different to the prime verb, $\beta=-2.66, S E=0.62, p<.001$. These results pattern similarly with those of Experiment 1.

\section{Combined analysis of Experiments 1 and 3}

To evaluate the effect of confederate accent on adaptation, the data from Experiments 1 and 3 were combined and analysed. This dataset comprised 1434 trials (957 from Experiment 1, 477 from Experiment 3). We used logistic mixed effects regression to model the outcome variable of whether or not the participant produced a DO description on each trial. We were interested in two comparisons: interaction with (a) a native vs. nonnative interlocutor, and (b) a weak accented vs. strong accented nonnative interlocutor. To make these comparisons, we represented confederate accent in our model using a Helmert contrast (Chambers \& Hastie, 1992), which compares each level of a category with the mean of the subsequent levels. Thus, the contrast included three levels: native (Experiment 1), weak nonnative (Experiment 1) and strong nonnative (Experiment 3). The other fixed effects were prime construction (PO vs. DO; mean-centred) and target verb parity (same verb vs. different verb; mean-centred). The model included by-participant random intercepts and slopes for all within-subject manipulations, and random intercepts for target verb and confederate ID. 
Of the 1434 target descriptions, $924(64.4 \%)$ were PO and $510(35.5 \%)$ were DO. Figure 4 shows the mean percentages of DO descriptions out of all valid target descriptions produced by participants in the two experiments.

The combined analysis indicated main effects of prime construction and target verb parity: Participants were more likely to produce a DO description following a DO prime, $\beta=2.24, S E=0.22, p<.001$, as well as when the target verb was different from the prime verb, $\beta=0.70, S E=0.18, p<.001$. There was a lexical boost effect, as indicated by a prime construction by target verb parity interaction: Participants were less likely to produce a DO description following a DO prime when the target verb was different to the prime verb $\beta=-2.64, S E=0.35, p>.001$. There were no effects of confederate accent nor their interaction with any of the other predictors (all $p>.1$ ).

\section{Discussion}

Experiment 3 explored adaptation in speakers during interaction with a nonnative confederate who spoke with a strong nonnative accent. The results align with those from Experiment 1, confirming that the structure of participants' target descriptions was influenced by that which their interlocutor produced immediately beforehand, with the effect enhanced by repetition of the verb between prime and target trial.

Importantly, there was no evidence to indicate that adaptation was dependent on the confederate's degree of accentedness. This was clear from our combined analysis of the two experiments, which showed no difference between interaction with a native and a nonnative speaker, or with a strong accented and a weak accented nonnative speaker. Thus, the strength of a nonnative interlocutor's accent does not appear to influence the degree to which a speaker adapts to their conversation partner. 


\section{Experiment 4}

Experiment 4 was intended to replicate the design of Experiment 1, where the confederate produced both DO and PO prime descriptions. To facilitate replication with a larger sample size, we conducted the experiment online using Amazon's crowdsourcing platform Mechanical Turk, with modifications to simulate real-time interaction with a partner using pre-recorded confederate utterances. We used recordings from one of the native confederates from Experiment 1 and the nonnative confederate from Experiment 3. Participants were informed that they would be playing a dialogue game with another participant in which they would alternate between describing a picture, and matching their partner's description to one of four pictures on their screen. They went on to receive similar instructions as in the lab-based experiment. The partner simulation was revealed in the debrief, and comments recorded via a post-test questionnaire were used as a basis to exclude participants who suspected that the audio was pre-recorded.

\section{Method}

Participants. 110 self-reported native English speakers were recruited via Amazon Mechanical Turk and paid $\$ 6$ to take part. ${ }^{6}$ We recruited participants who possessed mturk qualifications indicating that they were based in the US. Participants were randomly assigned to the native confederate or nonnative confederate condition. We excluded from the final dataset participants who did not complete the experiment (9) or who indicated post-test that they suspected their partner was a recording (4). A further one participant who produced only the verb on every trial was excluded. Thus

\footnotetext{
${ }^{6}$ Participants who did not complete the experiment and who contacted us were paid according to the proportion of trials they completed.
} 
the final dataset consisted of 96 participants - 48 per confederate condition.

Materials and design. The visual materials were the same as those used in Experiment 1. One of the native confederates from Experiment 1 and the nonnative confederate from Experiment 3 were used to simulate the native and nonnative partner respectively. Trial lists for each lab experiment session that the two confederates had taken part in were used as a base to generate the experiment stimuli. We first created the audio associated with each trial list by taking the trial by trial recordings of the confederate in the original lab session. These were minimally edited to remove traces of any dialogue between the confederate and participant to yield a single utterance for each trial. The original trial lists were then randomly shuffled whilst maintaining the same order constraints as Experiment 1 to generate 1000 new trial lists (500 per condition). Each run of the experiment randomly selected a trial list from the set of 1000. A large pool of potential trial lists was used to reduce the probability of multiple participants being exposed to the same trial list.

In addition, we also recorded a "partner greeting" from each of the two confederates, in which they introduced themselves by name and stated whether or not they were a native speaker of English. This was used in the audio check phase of the experiment (see next section).

Procedure. The entire experiment was conducted online on Amazon Mechanical Turk. Before beginning, participants were presented with a task description and an electronic consent form. The task was described as an interactive game which involved describing and matching pictures with a partner. After accepting the task, participants completed an audio check in which they were told to record a greeting to send to their partner. Participants were instructed to mention whether they were a 
native or nonnative speaker in the greeting. They then saw a series of instructions screens explaining the experiment procedure, followed by a 60 second wait to simulate a partner signing up to the task. Participants were then played a greeting ostensibly recorded by their partner, which revealed whether they were paired with a native or a nonnative speaker for the task. This step was analogous to the oral language history questionnaire conducted in the lab-based experiments.

During the experiment, participants' descriptions were recorded through their internal microphone via their web browser. On description trials, a microphone symbol highlighted in orange was shown on screen to indicate that they were being recorded. Participants were told to click on the microphone to stop recording, which would initiate playback on their partner's computer. A "waiting for your partner" message then appeared and remained on screen for a short delay before progressing on to a match trial. On match trials, participants saw a match array and playback of the associated confederate recording began after a short delay. The delays to simulate a partner speaking or selecting an image were of random duration, based on duration of participants' responses in the lab experiments; delays on the first few trials were long, to simulate a participant unfamiliar with the experiment interface, before declining to steady (but variable) duration. All sessions began with the partner describing and the participant matching.

At the end, participants were presented with a questionnaire collecting demographic information (age, gender, whether they were a native or nonnative speaker of English, and any other languages spoken) as well as any comments they had about the experiment. Participants who indicated suspicion that they were playing with a real partner in their comments were excluded from analysis. 
Coding and analysis. We followed the same coding and analysis procedures as in Experiment 1.

\section{Results}

Recordings for 4 trials were missing due to error writing data to the server. Of the remaining 2300 target descriptions, 1543 were coded as PO (67.1\%), 723 were coded as DO $(31.4 \%)$, and 34 were coded as other (1.5\%). These figures are comparable to those obtained in the lab version of the experiment. Figure 5 shows the mean percentages of DO descriptions out of all valid target descriptions recorded in each condition.

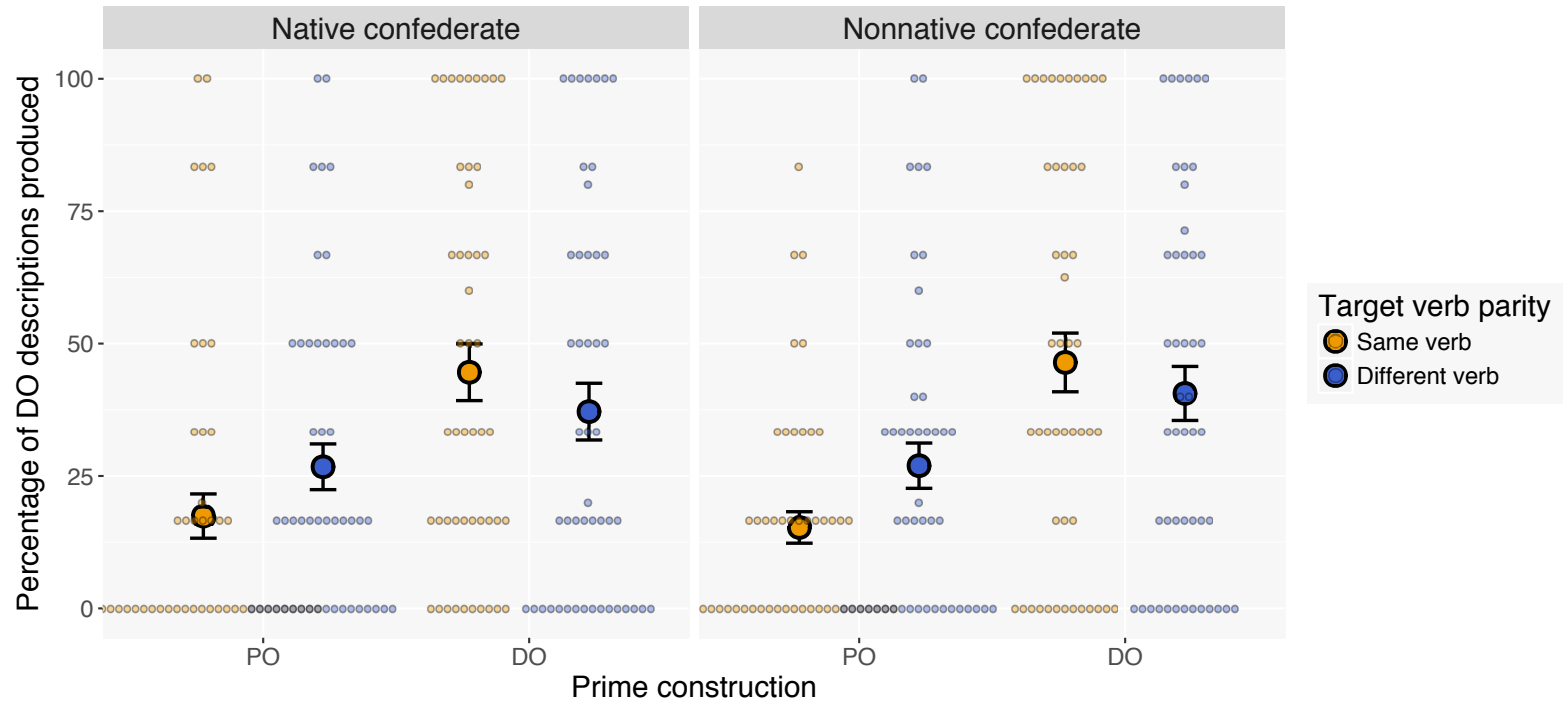

Figure 5. Mean percentages of DO descriptions produced in each condition in Experiment 4. Percentages were calculated out of the total number of valid descriptions (i.e. all descriptions coded as PO or DO) recorded in each condition. Error bars represent \pm 1 standard error of by-participant means. Dots represent individual participant means.

The model showed a main effect of prime construction: Participants were more likely to produce a DO description following a DO prime from the confederate, 
$\beta=1.45, S E=0.26, p<.001$. There was also a lexical boost effect as indicated by a prime construction by target verb parity interaction: Participants were less likely to produce a DO description following a DO prime if prime and target verb differed compared to when they were the same $\beta=-1.54, S E=0.36, p<.001$. There was no interaction between prime construction and confederate, indicating that participants were equally likely to produce a DO description following a DO prime when interacting with a native and a nonnative confederate $(p=.6)$. These results are largely consistent with those of Experiment 1.

\section{Discussion}

Experiment 4 was designed to replicate Experiment 1 with a larger sample size using online data collection. The results corroborate those from Experiment 1, confirming that the structure of participants' descriptions was influenced by that which the confederate produced immediately before, with the effect enhanced by lexical repetition of the verb between the prime and target trial. As with Experiment 1, there was no difference in the degree of adaptation during interaction with a native and a nonnative interlocutor.

In addition to verifying the results of Experiment 1, the experiment provides evidence that the syntactic priming effects seen in laboratory settings is not limited to face-to-face dialogue, but can be replicated in remote, web-based interaction. This extends previous work employing web-based methods to investigate syntactic priming in non-interactive contexts (Corley \& Scheepers, 2002; Weatherholtz et al., 2014), and adds to a growing body of work demonstrating the viability of online platforms as an alternative to traditional laboratory settings for collecting empirical data (Bartneck, Duenser, Moltchanova, \& Zawieska, 2015; Enochson \& Culbertson, 2015). 


\section{Experiment 5}

Experiment 5 was intended to replicate the design of Experiment 2, where rather than alternating between PO and DO constructions the confederate exclusively produced DO constructions, including in cases where these were ungrammatical. In the lab-based version of this experiment, we saw more adaptation to nonnative compared to native confederates. To facilitate replication with a larger sample size, the experiment was conducted online on Amazon Mechanical Turk. We used the same materials from Experiment 2 and followed the same procedure as Experiment 4.

\section{Method}

Participants. 108 self-reported native English speakers were recruited via Amazon Mechanical Turk and paid $\$ 6$ to take part. We recruited participants who possessed mturk qualifications indicating that they were based in the US. Participants were randomly assigned to the native confederate or nonnative confederate condition. Data were subsequently excluded from participants who did not complete the experiment (6), who indicated post-test that they suspected their partner was a recording (5), or due to recording failure (1). Thus the final dataset consisted of 96 participants - 47 and 49 in the native and nonnative confederate conditions respectively.

Materials and design. The visual materials were the same as those used in Experiment 2. Audio recordings from one of the native confederates and one of the nonnative confederates ('strongly accented'; native language Mandarin) from Experiment 2 were used to simulate the native and nonnative partner respectively. The nonnative confederate was the same confederate used in Experiments 3 and 4. Trial lists and audio stimuli were generated in the same way as in Experiment 4. As in the 
lab version, each experiment run began with a block of 20 filler items which included several ditransitive prime descriptions (including ungrammatical DOs), allowing participants to take note of their partner's unusual syntactic behaviour.

Procedure. This was identical to Experiment 4.

Coding and analysis. We followed the same coding and analysis procedure as in Experiment 2.

\section{Results}

Recordings for 7 trials were missing due to error writing data to the server. Of the remaining 2297 target descriptions, 1656 were coded as PO (72.1\%), 605 were coded as DO $(26.3 \%)$, and 36 were coded as other. These figures are comparable to those obtained in the lab version of the experiment. Figure 6 shows the mean percentages of DO descriptions out of all valid target descriptions recorded in each condition.

The model showed main effects of target verb type and target verb parity: Participants were less likely to produce a DO description with non-alternating target verbs, $\beta=-3.07, S E=0.91, p<.001$, as well as when the target verb differed from the prime verb, $\beta=-0.98, S E=0.25, p<.001$. These results are consistent with those of Experiment 2. There was also a main effect of confederate. This effect was in the opposite direction to that observed in Experiment 2: Participants were less likely to produce a DO description when interacting with the nonnative than the native confederate, $\beta=-1.29, S E=0.50, p=.01$. There was a target verb type by confederate interaction, indicating that participants were less likely to produce a DO description with non-alternating target verbs when interacting with the nonnative confederate, $\beta=-1.38, S E=0.61, p=.02$; in other words, participants produced more ungrammatical DO descriptions with the native confederate. Finally, there was a prime 


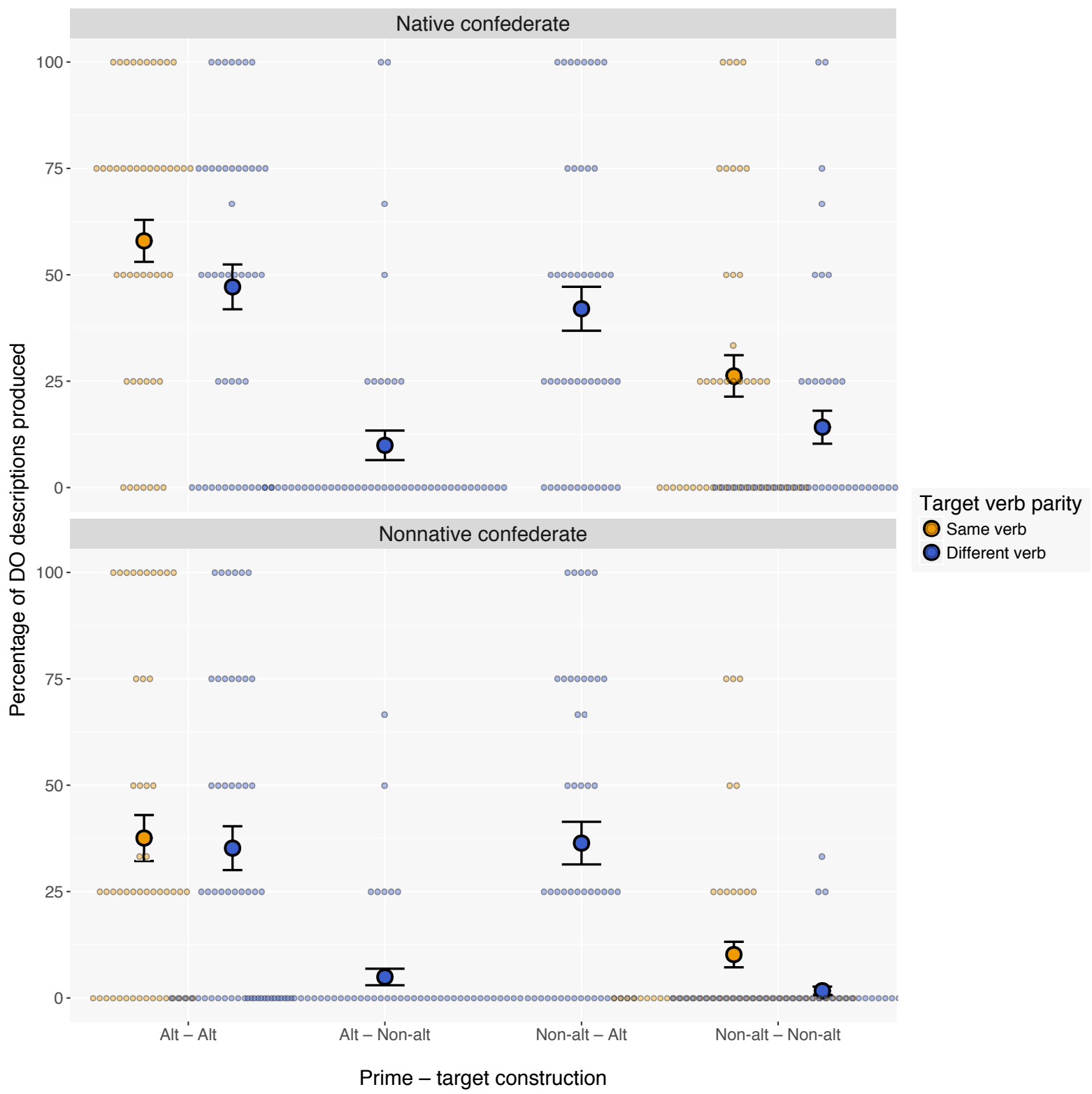

Figure 6. Mean percentages of DO descriptions produced in each condition in Experiment 2. Percentages were calculated out of the total number of valid descriptions (i.e. all descriptions coded as PO or DO) recorded in each condition. Error bars represent \pm 1 standard error of by-participant means. Dots represent individual participant means. The x-axis labels denote the verbs used by the confederate and the participant in the prime and target trials respectively, e.g. Alt-Alt indicates that the both the confederate and the participant produced descriptions involving an alternating verb which permits either a PO or a DO construction. All DO descriptions produced by participants in the non-alternating target conditions were ungrammatical. 
type by target verb type by confederate interaction, indicating that participants were less likely to produce a DO description with non-alternating target verbs following an alternating prime when interacting with the nonnative confederate, $\beta=-2.29$, $S E=0.86, p=.01$. This reflects that the increased ungrammatical DO priming with the native confederate was less pronounced following alternating primes.

\section{Combined analysis of Experiments 2 and 5}

To verify the different effect of confederate in the lab-based and the online versions of the experiment, we ran an additional analysis comparing the data from Experiments 2 and 5. The fixed and random effects of the model were identical to those used in each experiment's analysis, with the additional predictors of site (lab vs. online; mean-centred) and the interaction between site and confederate.

Figure 7 shows the mean percentages of DO descriptions out of all valid target descriptions produced by participants in each version of the experiment. The results showed a main effect of site: Participants were more likely to produce DO descriptions in the online version of the experiment, $\beta=1.50, S E=0.51, p=.003$. Importantly, there was an interaction between site and confederate, $\beta=-2.40, S E=0.71, p<.001$, reflecting that participants were more likely to produce DO descriptions with the nonnative confederate in the lab experiment but more likely to do so with the native confederate in the online experiment. In other words, the differential adaptation to natives and nonnatives that we observed in each experiment was in opposite directions.

\section{Discussion}

Experiment 5 was designed to replicate Experiment 2 with a larger sample size using online data collection. Thus, as with Experiment 2, the syntactic behaviour of 


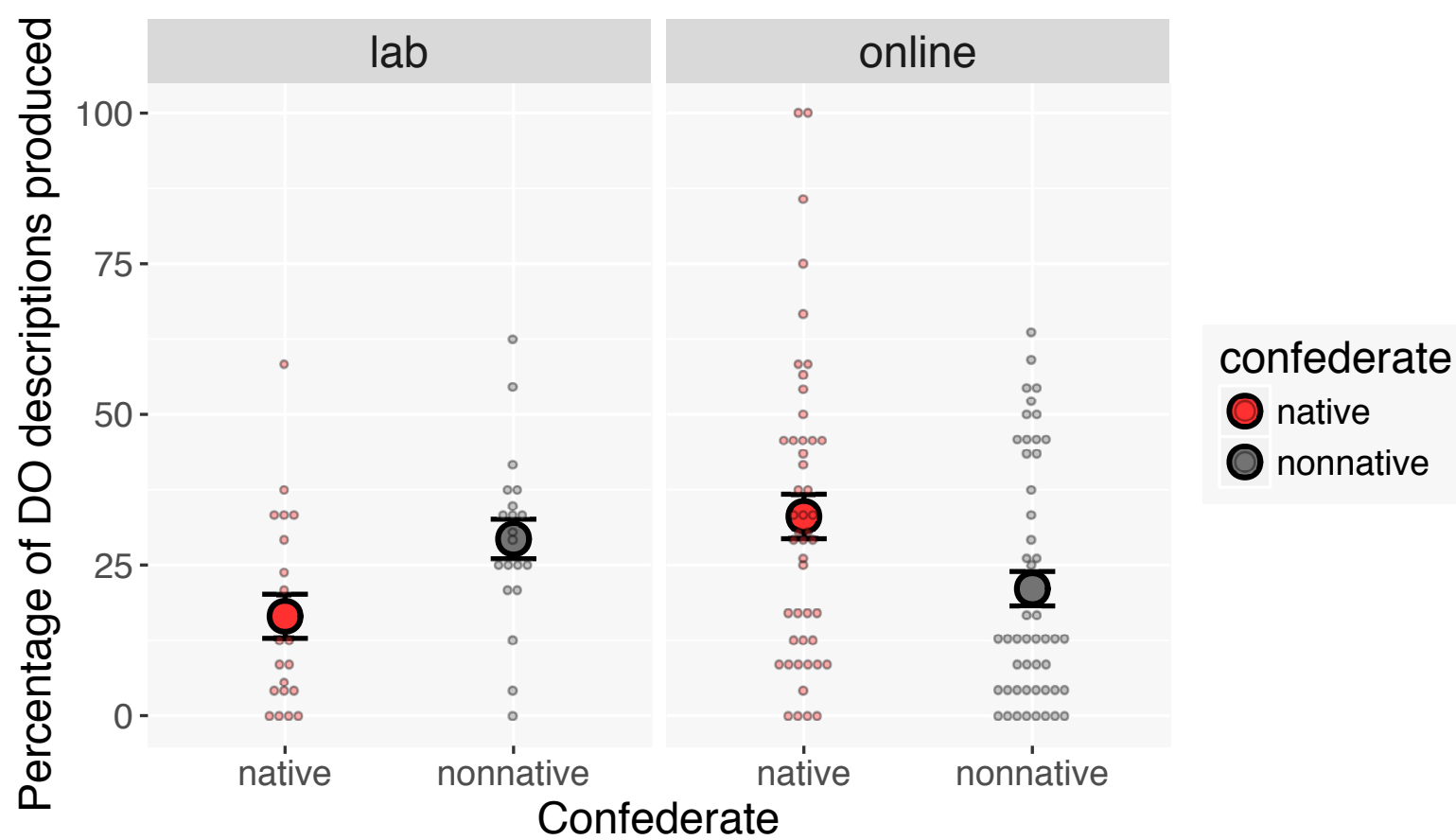

Figure 7. Mean percentages of DO descriptions produced in each confederate condition in Experiments 2 (lab) and 5 (online). Percentages were calculated out of the total number of valid descriptions (i.e. all descriptions coded as PO or DO) recorded in each condition. Error bars represent \pm 1 standard error of by-participant means. Dots represent individual participant means.

confederates was marked in that they only produced DO prime descriptions, half of which were ungrammatical.

The experiment revealed two main findings. Firstly, we observed a notable proportion of ungrammatical target descriptions with non-alternating verbs that participants produced (20\% of all DO descriptions recorded). This is consistent with Experiment 2, and additionally demonstrates that the priming of such ungrammatical DO constructions can arise even in remote interaction where speakers are not physically co-present.

Secondly, the results showed an effect of confederate, indicating that participants 
adapted differently to native and nonnative interlocutors. However, this effect was in the opposite direction to that of Experiment 2, where we found more DO descriptions in the nonnative confederate condition, reflecting greater adaptation toward the language of nonnative interlocutors. Conversely, here, participants produced more DO descriptions when interacting with the native confederate. We return to the mismatched direction of effects in Experiments 2 and 5 in a moment. However, it is worth noting that Experiment 5 does provide evidence of a listener-oriented account of adaptation, where speakers adapt differently during interaction with a native and a nonnative interlocutor. The fact that we found more DO descriptions with native interlocutors may point towards an accommodation-based explanation, rather than adaptation designed to facilitate communication. Specifically, speakers may have been reluctant to adapt to nonnative interlocutors who produced ungrammatical syntactic constructions in attempt to distance themselves from their partner's linguistic background (Giles, 1973). Such an explanation is consistent with findings from phonetic accommodation which demonstrate that in contrast to native-native conversation, both native speakers of English as well as those of Korean diverged from the speech of a nonnative interlocutor (M. Kim et al., 2011). Costa et al. (2008) also note that native speakers may on occasion restructure nonnative expressions to make them grammatically correct. This behaviour can be driven by the goal of facilitating learning for the nonnative speaker (cf. Margić, 2017). Participants in Experiment 5 may have thus been motivated either to distance themselves linguistically from their nonnative partner, or to implicitly correct their nonnative partner's ungrammatical language use, consequently increasing their production of grammatical PO sentences. Notably, this explanation is supported by the fact that we observed more ungrammatical DO descriptions with the native 
compared to the nonnative confederate, suggesting that speakers were less inclined to adapt to ungrammatical syntax when it was produced by a nonnative partner. This supports the idea of a didactic component to the range of linguistic modifications that constitute a nonnative-directed speech register (cf. Ferguson, 1975; Scarborough et al., 2007; Uther et al., 2007). It is perhaps surprising, however, that speakers did not behave similarly in Experiment 2, where confederates exhibited the same ungrammatical syntactic behaviour. We discuss this conflicting result in the General Discussion.

\section{General Discussion}

This study examined the degree of syntactic adaptation in dialogue, looking at interaction between native speakers of English and a native or nonnative interlocutor. We considered different mechanisms for syntactic adaptation: Automatic priming, where speakers (unconsciously) repeat recently heard structures; and listener-oriented mechanisms, in which speakers formulate utterances with respect to their interlocutor. We reasoned that if adaptation is influenced by listener-oriented mechanisms, speakers should consider their partner's apparent linguistic knowledge and communicative needs, resulting in different degrees of adaptation with native and nonnative interlocutors.

In the experiments reported, speakers took turns to describe and match pictures with a confederate partner, who produced prime descriptions on each turn according to a script. Experiments 1, 3 and 4 focussed on extending previous syntactic priming results to the context of native-nonnative interaction, while Experiments 2 and 5 aimed to emphasise the confederate's communicative needs by creating the impression of linguistic inflexibility. In line with previous confederate priming studies (e.g. Branigan et al., 2000), we found that speakers tended to produce the same syntactic form (PO or DO) that the confederate had just produced, with the effect magnified by lexical 
repetition of the verb between prime and target. This effect was found to extend to interaction with a nonnative confederate, although the degree of adaptation did not differ between native and nonnative confederates (Experiment 1). The effect was also similar regardless of the nonnative confederate's degree of accentedness (Experiment 3), and held even during remote interaction where speakers only had access to an auditory channel (Experiment 4). However, Experiments 2 and 5 revealed that when the confederate's grammatical competence was forefronted by their syntactic behaviour, speakers adapted to different degrees with a native and a nonnative interlocutor.

\section{Implications for mechanisms underlying adaptation}

Together, our results provide evidence for the role of listener-oriented mechanisms underlying adaptation. Speakers appeared to take into account information about their partner - in this case whether they were a native or nonnative speaker - and adjusted their language use accordingly; however, this information appeared to be relevant only under certain communicative contexts - specifically when partners exhibited linguistic inflexibility through their rigid production of (sometimes ungrammatical) DO constructions. The fact that speakers seemingly considered the grammatical forms their partner demonstrated familiarity with implies that adaptation is more than just an automatic link by which perception primes action. Rather, it suggests a flexible, dynamic process in which speakers adapt differently to different partners, based on an inference about the linguistic needs or characteristics of their partner. This finding complements results from a small but growing body of work highlighting the influence of socio-perceptual factors on phonetic (Enzinna, 2018; M. Kim et al., 2011) and syntactic (Balcetis \& Dale, 2005; Weatherholtz et al., 2014) adaptation.

However, speakers' perception of their partner's communicative needs appeared to 
influence their behaviour differently in different experimental contexts; we found opposite patterns of listener-dependent adaptation in Experiments 2 and 5, despite confederates exhibiting similar ungrammatical behaviour in both experiments. There are several potential explanations for the conflicting results. Firstly, differences in participant pools may have contributed to the divergence. Participants in Experiment 2 were recruited on the university's careers service website and hence likely comprised a relatively homogenous sample of undergraduate students based in the UK. In contrast, participants in Experiment 5 were Amazon Mechanical Turk workers based in the US - a population that is typically more heterogenous, with a larger range in age, ethnicity, and educational background, as well as a more balanced gender split (Enochson \& Culbertson, 2015; Mason \& Suri, 2012; Weinberg, Freese, \& McElhattan, 2014). Researchers have debated the external validity of studies relying on student participants, who may for instance be more susceptible to social influences, particularly in a laboratory experiment setting (Carpenter, Burks, \& Verhoogen, 2005; Sears, 1986). Such a bias may have contributed to a stronger tendency to adapt to nonnative partners in order to facilitate communication, resulting in the pattern of adaptation we saw in Experiment 2. Experiment 2 also has the disadvantage of a smaller sample size. This likely contributed to the relatively small effect size of confederate that we observed. This, in conjunction with the substantial variation that individuals tend to show in terms of propensity to adapt (Gill, Harrison, \& Oberlander, 2004; Kidd, 2012; Tobar-Henriquez, Rabagliati, \& Branigan, 2019), meant that the experiment was likely more susceptible to spurious effects (cf. Weatherholtz et al., 2014).

Finally, differences in experimental conditions (lab-based, face-to-face vs. online, remote interaction) could have elicited different patterns of adaptation in the two 
experiments. Although several recent studies highlight the comparability of psycholinguistic data from online crowdsourcing platforms and traditional lab settings (Demberg, 2013; Enochson \& Culbertson, 2015; Schnoebelen \& Kuperman, 2010), most of these do not involve tasks that target interaction and interpersonal behaviour. Psychological research however highlights the impact of physical co-presence in shaping communicative behaviour - in particular, factors such as anonymity and a shift away from social norms have been attributed to a disinhibition effect associated with online communication (Joinson, 2003; Lapidot-Lefler \& Barak, 2012; Suler, 2004). Such factors may be similarly relevant in the context of accommodation: Speakers in the lab-based experiment may have been conscious of appearing uncooperative or rude by diverging from their partner's productions; conversely, online participants may have been less adverse to appearing contradictory, or more inclined to implicitly correct their partner's grammar if they felt a need to. Research on dialogue also shows that conversations involving negotiation are more successful when participants can both see and hear each other than when they are restricted to only audio communication (Veinott, Olson, Olson, \& Fu, 1999). This highlights the importance of eye-contact in fostering social affinity and cooperative behaviour between interlocutors (cf. Lapidot-Lefler \& Barak, 2012). Given the central role of eye-contact in interpersonal interaction, it seems unsurprising then that its presence or absence may have a significant impact on socially-driven adaptation.

Although the two experiments show diverging results, the fact that they both demonstrate differential adaptation with native and nonnative interlocutors provides evidence for listener-oriented adaptation. We speculate that differences in experimental contexts may have contributed to the divergence: Face-to-face interaction in Experiment 
2 may have encouraged audience design processes, such as attempts to facilitate communication with a nonnative partner, whilst the remote nature of Experiment 5 may have meant that accommodation processes like a desire to disaffiliate oneself from a nonnative partner's linguistic background were at work. Importantly, both are consistent with an account of adaptation that takes listener-specific information into consideration; the full picture, however, is likely a complex phenomenon influenced by many factors, with situational context and communicative goals coming into play (e.g. Balcetis \& Dale, 2005; Branigan et al., 2007; Weatherholtz et al., 2014).

We also note that while our results support listener-oriented adaptation, they do not go against a priming-based account. In fact, automatic priming effects appear sufficient to explain the adaptation we observed in Experiments 1, 3 and 4, which was similar across native and nonnative interlocutors. One might also argue that priming could explain the pattern of adaptation in Experiment 5: Native speakers may for instance be less susceptible to priming from a nonnative partner due to greater differences in various aspects of production (e.g. speech rate, phonology, prosody; Costa et al., 2008). However, such an explanation implies that we should expect a similar pattern of adaptation in Experiment 2, undermining the validity of priming as the sole mechanism in Experiment 5. Moreover, it would also predict decreased levels of adaptation during interaction with strongly accented nonnative confederates, such as in Experiments 3 and 4; however this was not borne out in our results. Automatic priming thus falls short of fully accounting for our results across the five experiments. Nevertheless, listener-oriented processes do not always appear to come into play, as evidenced by Experiments 1, 3 and 4. This disparity could be reconciled by an account of adaptation that assumes some degree of automatic priming, but takes into 
consideration listener-specific information when the communicative context elicits a relevant inference, prompting specific goals such as a desire to facilitate communicative success (e.g. Branigan et al., 2011), to achieve social distance (e.g. M. Kim et al., 2011), or to convey ideological similarity (e.g. Weatherholtz et al., 2014). Thus, the nature of the mechanisms behind adaptation may by driven by the extent to which such information is relevant to the goals of interlocutors, influencing the pattern of adaptation observed. Such an account is also consistent with Branigan et al.'s (2011) communicative design account of alignment, as well as Costa et al.'s (2008) modified version of the automatic priming proposed by Pickering and Garrod (2004) to account for differential adaptation with native and nonnative interlocutors.

\section{Limitations and future possibilities}

The fact that at least in some communicative contexts, adaptation seems to depend on listener-specific information raises further questions about the time-course with which such information may be brought to bear, and the additional cost in speakers building complex situational models depending on the context. It has been shown, for example, that speakers take longer to initiate descriptions for objects that they recognise as unfamiliar to their listener, even if they themselves have previously described the object (Horton \& Gerrig, 2005). More generally, studies demonstrate a cost for speakers to tailor their descriptions to specific addressees in a given context, and limitations to the extent they are able to do so (e.g. Ferreira, Slevc, \& Rogers, 2005; Horton \& Keysar, 1996; Keysar, Barr, \& Horton, 1998; Keysar et al., 2003; Wardlow Lane \& Ferreira, 2008). It is likely that the task employed in the current study was simple enough for speakers to adapt strategically when the opportunity presented itself, converging with or diverging from their partner depending on their 
goals or intentions. To that end, our results are informative about syntactic adaptation of the dative construction with native and nonnative interlocutors; however, it is possible that we find less evidence for listener-oriented adaptation in other contexts, such as in a task involving more complex target descriptions, or if speakers were under greater cognitive load (cf. Horton \& Gerrig, 2005).

We also note that fundamental differences between Experiments 2 and 5 prevent us from pinpointing the exact mechanism underlying the listener-oriented adaptation that we observed. It is clear that speakers adapted differently to native and nonnative interlocutors, which we attribute to an inference about their partner's linguistic needs or knowledge. However, we cannot determine the extent to which incidental factors such as experimental platform (laboratory vs. online), sample population (UK- vs. US-based), or nature of interaction (face-to-face vs. remote) may have affected how this inference shaped speakers social and/or communicative goals, and in turn the way they adapted to their partner. A more systematic comparison of how different modes of communication (e.g. audiovisual vs. audio only) influence adaptation in different communicative settings is needed to tease apart these variables. More broadly, this limitation is also pertinent to a growing trend in psycholinguistics towards web-based methods for collecting empirical data. Although several recent studies show that existing laboratory results can be replicated online (Demberg, 2013; Enochson \& Culbertson, 2015; Keller, Gunasekharan, Mayo, \& Corley, 2009), and other studies demonstrate the promise of web-based methods for investigating phenomena such as adaptation (Weatherholtz et al., 2014), less work has been done using web-based paradigms for real-time, interactive tasks between pairs (or groups) of speakers. While online platforms no doubt offer a large-scale, low-resource alternative to lab-based data 
collection, more work is needed on whether and how this compares with traditional methods for tasks involving social interaction.

\section{Conclusions}

We reported five experiments in which we examined syntactic adaptation in dialogue, comparing interaction between native speakers of English and an interlocutor who was a native or a nonnative speaker. We found different levels of adaptation towards native and nonnative interlocutors only when the syntactic behaviour of interlocutors elicited an inference about their linguistic needs or knowledge. We interpret these results as demonstrating that speakers took into account information about their partner - in this case whether they were a native or nonnative speaker - when this information was foregrounded by their partner's linguistic behaviour. These results provide evidence that syntactic adaptation is at least partly driven by listener-oriented mechanisms; the exact nature of this adaptation is likely influenced by how and the degree to which partner-specific information is relevant to the goals of the parties involved. Hence, adaptation is more than just an unconscious tendency towards repetition; rather, it is a flexible, dynamic process which takes into consideration the social and communicative goals of an exchange. 
References

Andruski, J. E., Kuhl, P. K., \& Hayashi, A. (1999). Point vowels in Japanese mothers' speech to infants and adults. The Journal of the Acoustical Society of America, $105(2), 1095-1096$.

Atkinson, M., Smith, K., \& Kirby, S. (2018). Adult learning and language simplification. Cognitive Science, 42(8), 2818-2854.

Babel, M. (2012). Evidence for phonetic and social selectivity in spontaneous phonetic imitation. Journal of Phonetics, 40(1), 177-189.

Balcetis, E. E., \& Dale, R. (2005). An exploration of social modulation of syntactic priming. In B. G. Bara, L. Barsalou, \& M. Bucciarelli (Eds.), Proceedings of the 27th Annual Meeting of the Cognitive Science Society (Vol. 27, pp. 184-189).

Barr, D. J. (2008). Pragmatic expectations and linguistic evidence: Listeners anticipate but do not integrate common ground. Cognition, 109(1), 18-40.

Bartneck, C., Duenser, A., Moltchanova, E., \& Zawieska, K. (2015). Comparing the similarity of responses received from studies in amazon's mechanical turk to studies conducted online and with direct recruitment. PLoS one, 10(4).

Bates, D., Maechler, M., Bolker, B., \& Walker, S. (2014). lme4: Linear mixed-effects models using Eigen and S4 [Computer software manual]. Retrieved from http://CRAN.R-project.org/package=lme4 (R package version 1.1-6)

Beebe, L. M. (1981). Social and situational factors affecting the communicative strategy of code-switching. International Journal of the Sociology of Language, 32, 139-149.

Bentz, C., \& Winter, B. (2014). Languages with more second language learners tend to lose nominal case. In S. Wichmann \& J. Good (Eds.), Quantifying language 
dynamics (pp. 96-124). Brill.

Beňuš, Š., Levitan, R., \& Hirschberg, J. (2012). Entrainment in spontaneous speech: the case of filled pauses in Supreme Court hearings. In Proceedings of the 3rd International Conference on Cognitive Infocommunications (pp. 793-797).

Bernolet, S., Hartsuiker, R. J., \& Pickering, M. J. (2012). Effects of phonological feedback on the selection of syntax: Evidence from between-language syntactic priming. Bilingualism: Language and Cognition, 15(3), 503-516.

Biersack, S., Kempe, V., \& Knapton, L. (2005). Fine-tuning speech registers: a comparison of the prosodic features of child-directed and foreigner-directed speech. In Ninth European Conference on Speech Communication and Technology (pp. 2401-2405).

Bock, K. (1986). Syntactic persistence in language production. Cognitive Psychology, $18(3), 355-387$.

Bock, K., \& Loebell, H. (1990). Framing sentences. Cognition, 35, 1-39.

Bortfeld, H., \& Brennan, S. E. (1997). Use and acquisition of idiomatic expressions in referring by native and non-native speakers. Discourse Processes, 23(2), 119-147.

Bosker, H. R., Quené, H., Sanders, T., \& De Jong, N. H. (2014). Native "um"s elicit prediction of low-frequency referents, but non-native "um"s do not. Journal of Memory and Language, 75, 104-116.

Braidi, S. M. (2002). Reexamining the role of recasts in native-speaker/nonnative-speaker interactions. Language Learning, 52(1), 1-42.

Branigan, H. P., Pickering, M. J., \& Cleland, A. A. (1999). Syntactic priming in written production: Evidence for rapid decay. Psychonomic Bulletin $\&$ Review, 6(4), 635-640. 
Branigan, H. P., Pickering, M. J., \& Cleland, A. A. (2000). Syntactic co-ordination in dialogue. Cognition, 75(2), B13-B25.

Branigan, H. P., Pickering, M. J., McLean, J. F., \& Cleland, A. A. (2007). Syntactic alignment and participant role in dialogue. Cognition, 104(2), 163-197.

Branigan, H. P., Pickering, M. J., Pearson, J., McLean, J. F., \& Brown, A. (2011). The role of beliefs in lexical alignment: Evidence from dialogs with humans and computers. Cognition, 121(1), 41-57.

Brennan, S. E., \& Clark, H. H. (1996). Conceptual pacts and lexical choice in conversation. Journal of Experimental Psychology: Learning, Memory, and Cognition, 22(6), 1482-1493.

Brennan, S. E., Galati, A., \& Kuhlen, A. K. (2010). Two minds, one dialog: Coordinating speaking and understanding. In B. H. Ross (Ed.), The Psychology of Learning and Motivation (Vol. 53, pp. 301-344). Academic Press.

Brennan, S. E., \& Hanna, J. E. (2009). Partner-specific adaptation in dialog. Topics in Cognitive Science, 1(2), 274-291.

Bresnan, J., \& Ford, M. (2010). Predicting syntax: Processing dative constructions in American and Australian varieties of English. Language, 86(1), 168-213.

Burnham, D., Kitamura, C., \& Vollmer-Conna, U. (2002). What's new, pussycat? On talking to babies and animals. Science, 296 (5572), 1435-1435.

Cai, Z. G., Pickering, M. J., \& Branigan, H. P. (2012). Mapping concepts to syntax: Evidence from structural priming in Mandarin Chinese. Journal of Memory and Language, 66(4), 833-849.

Campbell, A. L., \& Tomasello, M. (2001). The acquisition of English dative constructions. Applied Psycholinguistics, 22(2), 253-267. 
Carpenter, J., Burks, S., \& Verhoogen, E. (2005). Comparing students to workers: The effects of social framing on behavior in distribution games. Research in Experimental Economics, 10, 261-290.

Chambers, J. M., \& Hastie, T. J. (1992). Statistical models in S (Vol. 251). Wadsworth \& Brooks/Cole Advanced Books \& Software Pacific Grove, CA.

Clark, H. H. (1996). Using language. Cambridge University Press.

Clark, H. H., \& Murphy, G. L. (1983). Audience design in meaning and reference. In J. F. LeNy \& W. Kintsch (Eds.), Language and comprehension (pp. 287-299). Amsterdam: North-Holland Publishing Co.

Clark, H. H., \& Schaefer, E. F. (1987). Concealing one's meaning from overhearers. Journal of Memory and Language, 26 (2), 209-225.

Cleland, A. A., \& Pickering, M. J. (2003). The use of lexical and syntactic information in language production: Evidence from the priming of noun-phrase structure. Journal of Memory and Language, 49(2), 214-230.

Combert, J. (1987). Are young children's speech adaptations conscious or automatic? A short theoretical note. International Journal of Psychology, 22(3), 375-382.

Conwell, E., \& Demuth, K. (2007). Early syntactic productivity: Evidence from dative shift. Cognition, 103(2), 163-179.

Corley, M., \& Scheepers, C. (2002). Syntactic priming in English sentence production: Categorical and latency evidence from an Internet-based study. Psychonomic Bulletin $\&$ Review, 9(1), 126-131.

Costa, A., Pickering, M. J., \& Sorace, A. (2008). Alignment in second language dialogue. Language and Cognitive Processes, 23(4), 528-556.

Demberg, V. (2013). Integration Costs on Auxiliaries?-a self-paced reading study using 
WebExp. In M. Knauff, M. Pauen, N. Sebanz, \& I. Wachsmuth (Eds.), Proceedings of the 35th Annual Meeting of the Cognitive Science Society (Vol. 35, pp. 2160-2165). Berlin, Germany.

Enochson, K., \& Culbertson, J. (2015). Collecting psycholinguistic response time data using amazon mechanical turk. PLoS one, $10(3)$.

Enzinna, N. R. (2018). Automatic and social effects on accommodation in monolingual and bilingual speech. In P. Farrell (Ed.), Proceedings of the linguistic society of america (Vol. 3, pp. 41:1-15). Salt Lake City, Utah. doi: 10.3765/plsa.v3i1.4333

Epley, N., Morewedge, C. K., \& Keysar, B. (2004). Perspective taking in children and adults: Equivalent egocentrism but differential correction. Journal of Experimental Social Psychology, 40(6), 760-768.

Ferguson, C. A. (1971). Absence of copula and the notion of simplicity: A study of normal speech, baby talk, foreigner talk and pidgins. In D. Hymes (Ed.), Pidginization and creolization of languages (pp. 141-150). New York: Cambridge University Press.

Ferguson, C. A. (1975). Toward a characterization of English foreigner talk. Anthropological Linguistics, 1-14.

Fernald, A., Taeschner, T., Dunn, J., Papousek, M., de Boysson-Bardies, B., \& Fukui, I. (1989). A cross-language study of prosodic modifications in mothers' and fathers' speech to preverbal infants. Journal of Child Language, 16(3), 477-501.

Fernández, R., \& Grimm, R. (2014). Quantifying categorical and conceptual convergence in child-adult dialogue. In Proceedings of the 36th Annual Meeting of the Cognitive Science Society (Vol. 36, pp. 463-468).

Ferreira, V. S., Slevc, L. R., \& Rogers, E. S. (2005). How do speakers avoid ambiguous 
linguistic expressions? Cognition, 96(3), 263-284.

Flett, S., Branigan, H. P., \& Pickering, M. J. (2013). Are non-native structural preferences affected by native language preferences? Bilingualism: Language and Cognition, 16(4), 751-760.

Foltz, A., Thiele, K., Kahsnitz, D., \& Stenneken, P. (2015). Children's syntactic-priming magnitude: lexical factors and participant characteristics. Journal of Child Language, 42(4), 932-945.

Frank, S., \& Smith, K. (2018). A model of linguistic accommodation leading to language simplification. In Proceedings of the 40th Annual Meeting of the Cognitive Science Society (pp. 390-395). PsyArXiv.

Gibson, E., Tan, C., Futrell, R., Mahowald, K., Konieczny, L., Hemforth, B., \& Fedorenko, E. (2017). Don't underestimate the benefits of being misunderstood. Psychological Science, 28(6), 703-712.

Giles, H. (1973). Accent mobility: A model and some data. Anthropological Linguistics, $87-105$

Giles, H., \& Coupland, N. (1991). Contexts of accommodation: Developments in applied sociolinguistics. New York: Cambridge University Press.

Giles, H., \& Ogay, T. (2008). Communication accommodation theory. In B. B. Whaley \& W. Samter (Eds.), Explaining communication: Contemporary theories and exemplars (pp. 293-310). New Jersey: Lawrence Erlbaum.

Gill, A. J., Harrison, A. J., \& Oberlander, J. (2004). Interpersonality: Individual differences and interpersonal priming. In K. Forbus, D. Gentner, \& T. Reiger (Eds.), Proceedings of the 26th Annual Meeting of the Cognitive Science Society (Vol. 26). Chicago, Illinois. 
Gries, S. T. (2005). Syntactic priming: A corpus-based approach. Journal of Psycholinguistic Research, 34(4), 365-399.

Hanna, J. E., \& Tanenhaus, M. K. (2004). Pragmatic effects on reference resolution in a collaborative task: Evidence from eye movements. Cognitive Science, 28(1), $105-115$.

Hanulíková, A., Van Alphen, P. M., Van Goch, M. M., \& Weber, A. (2012). When one person's mistake is another's standard usage: The effect of foreign accent on syntactic processing. Journal of Cognitive Neuroscience, 24(4), 878-887.

Hartsuiker, R. J., Bernolet, S., Schoonbaert, S., Speybroeck, S., \& Vanderelst, D. (2008). Syntactic priming persists while the lexical boost decays: Evidence from written and spoken dialogue. Journal of Memory and Language, 58(2), 214-238.

Hartsuiker, R. J., Pickering, M. J., \& Veltkamp, E. (2004). Is syntax separate or shared between languages? Cross-linguistic syntactic priming in Spanish-English bilinguals. Psychological Science, 15(6), 409-414.

Haywood, S. L., Pickering, M. J., \& Branigan, H. P. (2005). Do speakers avoid ambiguities during dialogue? Psychological Science, 16(5), 362-366.

Healey, P. G., Purver, M., \& Howes, C. (2014). Divergence in dialogue. PloS One, 9(6), e98598.

Horton, W. S., \& Gerrig, R. J. (2005). The impact of memory demands on audience design during language production. Cognition, 96(2), 127-142.

Horton, W. S., \& Keysar, B. (1996). When do speakers take into account common ground? Cognition, 59(1), 91-117.

Hwang, J., Brennan, S. E., \& Huffman, M. K. (2015). Phonetic adaptation in non-native spoken dialogue: Effects of priming and audience design. Journal of 
Memory and Language, 81, 72-90.

Iio, T., Shiomi, M., Shinozawa, K., Shimohara, K., Miki, M., \& Hagita, N. (2015). Lexical entrainment in human robot interaction. International Journal of Social Robotics, 7(2), 253-263.

Ireland, M. E., \& Pennebaker, J. W. (2010). Language style matching in writing: Synchrony in essays, correspondence, and poetry. Journal of Personality and Social Psychology, 99(3), 549-571.

Isaacs, E. A., \& Clark, H. H. (1987). References in conversation between experts and novices. Journal of Experimental Psychology: General, 116(1), 26.

Ivanova, I., Costa, A., Pickering, M. J., \& Branigan, H. (2007). Lexical alignment of L1 speakers with L2 speakers. Turku, Finland. (Poster presented at the 13th Architectures and Mechanisms for Language Processing (AMLaP) Conference) Ivanova, I., Pickering, M. J., McLean, J. F., Costa, A., \& Branigan, H. P. (2012). How do people produce ungrammatical utterances? Journal of Memory and Language, $67(3), 355-370$.

Jaeger, T. F., \& Snider, N. E. (2013). Alignment as a consequence of expectation adaptation: Syntactic priming is affected by the prime's prediction error given both prior and recent experience. Cognition, 127(1), 57-83.

Joinson, A. N. (2003). Understanding the psychology of internet behavior: Virtualworlds, real lives. New York: Palgrave Macmillan.

Keller, F., Gunasekharan, S., Mayo, N., \& Corley, M. (2009). Timing accuracy of web experiments: A case study using the WebExp software package. Behavior Research Methods, 41(1), 1-12.

Keysar, B., Barr, D. J., \& Horton, W. S. (1998). The egocentric basis of language use: 
Insights from a processing approach. Current Directions in Psychological Science, $7(2), 46-49$.

Keysar, B., Lin, S., \& Barr, D. J. (2003). Limits on theory of mind use in adults. Cognition, 89(1), 25-41.

Kidd, E. (2012). Individual differences in syntactic priming in language acquisition. Applied Psycholinguistics, 33(2), 393-418.

Kim, M., Horton, W. S., \& Bradlow, A. R. (2011). Phonetic convergence in spontaneous conversations as a function of interlocutor language distance. Laboratory Phonology, 2(1), 125-156.

Kim, Y., \& McDonough, K. (2008). The effect of interlocutor proficiency on the collaborative dialogue between Korean as a second language learners. Language Teaching Research, 12(2), 211-234.

Knoll, M., Scharrer, L., \& Costall, A. (2009). Are actresses better simulators than female students? The effects of simulation on prosodic modifications of infant-and foreigner-directed speech. Speech Communication, 51(3), 296-305.

Knoll, M., \& Uther, M. (2004). Motherese and Chinese: Evidence of acoustic changes in speech directed at infants and foreigners. The Journal of the Acoustical Society of America, 116(4), 2522-2522.

Kuhl, P. K., Andruski, J. E., Chistovich, I. A., Chistovich, L. A., Kozhevnikova, E. V., Ryskina, V. L., ... Lacerda, F. (1997). Cross-language analysis of phonetic units in language addressed to infants. Science, 277(5326), 684-686.

Lapidot-Lefler, N., \& Barak, A. (2012). Effects of anonymity, invisibility, and lack of eye-contact on toxic online disinhibition. Computers in Human Behavior, 28(2), 434-443. 
Levelt, W. J., \& Kelter, S. (1982). Surface form and memory in question answering. Cognitive Psychology, 14(1), 74-106.

Lockridge, C. B., \& Brennan, S. E. (2002). Addressees' needs influence speakers' early syntactic choices. Psychonomic Bulletin \& Review, 9(3), 550-557.

Loebell, H., \& Bock, K. (2003). Structural priming across languages. Linguistics, $41(5), 791-824$.

Long, M. H. (1981). Questions in foreigner talk discourse. Language Learning, 31(1), $135-157$.

Long, M. H. (1983). Native speaker/non-native speaker conversation and the negotiation of comprehensible input. Applied Linguistics, 4 (2), 126-141.

Lupyan, G., \& Dale, R. (2010). Language structure is partly determined by social structure. PloS one, 5(1), e8559.

Mahowald, K., James, A., Futrell, R., \& Gibson, E. (2016). A meta-analysis of syntactic priming in language production. Journal of Memory and Language, 91, 5-27.

Margić, B. D. (2017). Communication courtesy or condescension? Linguistic accommodation of native to non-native speakers of English. Journal of English as a Lingua Franca, 6(1), 29-55.

Mason, W., \& Suri, S. (2012). Conducting behavioral research on Amazon's Mechanical Turk. Behavior Research Methods, 44(1), 1-23.

Matthews, D., Lieven, E., \& Tomasello, M. (2010). What's in a manner of speaking? Children's sensitivity to partner-specific referential precedents. Developmental Psychology, 46(4), 749-760.

Meisel, J. M. (1976). Linguistic simplification: A study of immigrant workers' speech and foreigner talk. In S. Felix (Ed.), Second language development: Trends and 
issues (pp. 13-41).

Metzing, C., \& Brennan, S. E. (2003). When conceptual pacts are broken:

Partner-specific effects on the comprehension of referring expressions. Journal of Memory and Language, 49(2), 201-213.

Nenkova, A., Gravano, A., \& Hirschberg, J. (2008). High frequency word entrainment in spoken dialogue. In Proceedings of the 46th annual meeting of the Association for Computational Linguistics on human language technologies: Short papers (pp. $169-172)$.

Papoušek, M., \& Hwang, S.-F. C. (1991). Tone and intonation in Mandarin babytalk to presyllabic infants: Comparison with registers of adult conversation and foreign language instruction. Applied Psycholinguistics, 12(4), 481-504.

Papoušek, M., Papoušek, H., \& Symmes, D. (1991). The meanings of melodies in motherese in tone and stress languages. Infant Behavior and Development, 14(4), $415-440$.

Pickering, M. J., \& Branigan, H. P. (1998). The representation of verbs: Evidence from syntactic priming in language production. Journal of Memory and Language, $39(4), 633-651$.

Pickering, M. J., \& Garrod, S. (2004). Toward a mechanistic psychology of dialogue. Behavioral and Brain Sciences, 27(2), 169-190.

Pickering, M. J., \& Garrod, S. (2006). Alignment as the basis for successful communication. Research on Language and Computation, 4(2-3), 203-228.

Prato-Previde, E., Fallani, G., \& Valsecchi, P. (2006). Gender differences in owners interacting with pet dogs: An observational study. Ethology, 112(1), 64-73.

R Core Team. (2016). R: A Language and Environment for Statistical Computing 
[Computer software manual]. Vienna, Austria. Retrieved from https://www.R-project.org/

Raffray, C. N., Pickering, M. J., Cai, Z. G., \& Branigan, H. P. (2014). The production of coerced expressions: Evidence from priming. Journal of Memory and Language, $74,91-106$.

Reitter, D., \& Moore, J. D. (2006). Priming of syntactic rules in task-oriented dialogue and spontaneous conversation. In Proceedings of the 28th Annual Meeting of the Cognitive Science Society (Vol. 28, pp. 685-690).

Savage, C., Lieven, E., Theakston, A., \& Tomasello, M. (2003). Testing the abstractness of children's linguistic representations: Lexical and structural priming of syntactic constructions in young children. Developmental Science, 6(5), 557-567.

Scarborough, R., Dmitrieva, O., Hall-Lew, L., Zhao, Y., \& Brenier, J. (2007). An acoustic study of real and imagined foreigner-directed speech. In M. J. Solé, D. Recasens, \& J. Romero (Eds.), Proceedings of the 15th International Congress of Phonetic Sciences (pp. 2165-2168). Causal Productions.

Schnoebelen, T., \& Kuperman, V. (2010). Using Amazon mechanical turk for linguistic research. Psihologija, 43(4), 441-464.

Schoonbaert, S., Hartsuiker, R. J., \& Pickering, M. J. (2007). The representation of lexical and syntactic information in bilinguals: Evidence from syntactic priming. Journal of Memory and Language, 56(2), 153-171.

Sears, D. O. (1986). College sophomores in the laboratory: Influences of a narrow data base on social psychology's view of human nature. Journal of Personality and Social Psychology, 51(3), 515-530.

Shepard, C. A., Giles, H., \& Le Poire, B. A. (2001). Communication accommodation 
theory. In W. P. R. . H. Giles (Ed.), The new handbook of language and social psychology (pp. 33-56). New York: Wiley.

Smith, C. (2007). Prosodic accommodation by French speakers to a non-native interlocutor. In Proceedings of the XVIth International Congress of Phonetic Sciences (pp. 313-348). Saarbrucken, Germany.

Smith, M., \& Wheeldon, L. (2001). Syntactic priming in spoken sentence production - an online study. Cognition, 78(2), 123-164.

Snow, C. E., Eeden, R., \& Muysken, P. (1981). The interactional origins of foreigner talk: Municipal employees and foreign workers. International Journal of the Sociology of Language, 1981(28), 81-92.

Snyder, W. (2001). On the nature of syntactic variation: Evidence from complex predicates and complex word-formation. Language, 324-342.

Snyder, W., \& Stromswold, K. (1997). The structure and acquisition of English dative constructions. Linguistic Inquiry, 281-317.

Staum Casasanto, L., Jasmin, K., \& Casasanto, D. (2010). Virtually accommodating: Speech rate accommodation to a virtual interlocutor. In Proceedings of the 32nd Annual meeting of the Cognitive Science Society (pp. 127-132).

Suler, J. (2004). The online disinhibition effect. Cyberpsychology \& Behavior, 7(3), $321-326$.

Tobar-Henriquez, A., Rabagliati, H., \& Branigan, H. (2019). Lexical entrainment reflects a stable individual trait: Implications for individual differences in language processing. Journal of Experimental Psychology: Learning, Memory and Cognition. doi: http://dx.doi.org/10.1037/xlm0000774

Trofimovich, P., Mcdonough, K., \& Neumann, H. (2013). Using collaborative tasks to 
elicit auditory and structural priming. TESOL Quarterly, 47(1), 177-186.

Uther, M., Knoll, M. A., \& Burnham, D. (2007). Do you speak E-NG-LI-SH? A comparison of foreigner-and infant-directed speech. Speech Communication, $49(1), 2-7$.

Varonis, E. M., \& Gass, S. M. (1985). Miscommunication in native/nonnative conversation. Language in Society, 14 (3), 327-343.

Veinott, E. S., Olson, J., Olson, G. M., \& Fu, X. (1999). Video helps remote work: Speakers who need to negotiate common ground benefit from seeing each other. In Proceedings of the SIGCHI conference on Human Factors in Computing Systems (pp. 302-309). Pittsburgh, Pennsylvania.

Wardlow, L. (2013). Individual differences in speakers' perspective taking: The roles of executive control and working memory. Psychonomic Bulletin $\&$ Review, 20(4), $766-772$.

Wardlow Lane, L., \& Ferreira, V. S. (2008). Speaker-external versus speaker-internal forces on utterance form: Do cognitive demands override threats to referential success? Journal of Experimental Psychology: Learning, Memory, and Cognition, $34(6), 1466-1481$.

Weatherholtz, K., Campbell-Kibler, K., \& Jaeger, T. F. (2014). Socially-mediated syntactic alignment. Language Variation and Change, 26 (3), 387-420.

Weinberg, J. D., Freese, J., \& McElhattan, D. (2014). Comparing data characteristics and results of an online factorial survey between a population-based and a crowdsource-recruited sample. Sociological Science, 1.

Wray, A., \& Grace, G. W. (2007). The consequences of talking to strangers: Evolutionary corollaries of socio-cultural influences on linguistic form. Lingua, 
$117(3), 543-578$.

Xu, N., Burnham, D., Kitamura, C., \& Vollmer-Conna, U. (2013). Vowel hyperarticulation in parrot-, dog- and infant-directed speech. Anthrozoös, 26 (3), $373-380$. 